\title{
THE POTENTIAL FOR IMAGING IN SITU DAMAGE IN INFLATABLE SPACE STRUCTURES
}

\author{
Eric I. Madaras ${ }^{1}$, Robert F. Anastasi ${ }^{2}$, Jeffrey P. Seebo ${ }^{3}$, George Studor ${ }^{4}$, Douglas L. \\ McMakin $^{5}$, Robert Nellums ${ }^{6}$, and William P. Winfree ${ }^{1}$ \\ ${ }^{1}$ NASA Langley Research Center, Nondestructive Evaluation Sciences Branch, MS 231 \\ Hampton, VA 23681 \\ ${ }^{2}$ U.S. Army Research Laboratory, Vehicle Technology Directorate, AMSRD-ARL-VT-SM, \\ Nondestructive Evaluation Sciences Branch, NASA Langley Research Center, MS 231, \\ Hampton, VA 23681 \\ ${ }^{3}$ Lockheed Martin, NASA Langley Research Center, MS 231, Hampton, VA 23681 \\ ${ }^{4}$ NASA Johnson Space Center, Structures Branch, ES2, Houston, TX \\ ${ }^{5}$ Pacific Northwest National Laboratory, Applied Physics, P.O. Box 999 MSIN:K2-31, \\ Richland, WA, 99354 \\ ${ }^{6}$ Sandia National Laboratory, P.O. Box 5800, Albuquerque, N.M. 87185
}

\begin{abstract}
NASA is investigating the use of inflatable habitat structures for orbital transfer and planetary applications. Since space structures are vulnerable to damage from micrometeoroid and orbital debris, it is important to investigate means of detecting such damage. This study is an investigation into methods for performing non-destructive evaluation (NDE) on inflatable habitat modules. Results of this work showed that various electromagnetic imaging modalities from microwaves to terahertz imaging have the greatest potential for a viable, portable, NDE tool which could possibly be deployed aboard an inflatable habitat module.
\end{abstract}

Keywords: Terahertz imaging, Millimeter wave imaging, Microwave imaging, Space NDE, Inflatable space structures.

PACS: 41.20.-q, 42.25.Bs, 81.70.Ex

\section{INTRODUCTION}

NASA is investigating the development of inflatable habitat structures for potential orbital, transfer, and planetary applications. (See Figure 1 for an example of a conceptual model of a lunar surface module.) The ability to monitor and assess the structural health of an inflatable module is an important factor in determining the feasibility of using inflatable technologies for habitat requirements, especially in the presence of micrometeoroid and orbital debris (MMOD) threats [1,2]. Hence, NASA is evaluating various non-destructive evaluation (NDE) methods for their ability to perform detection, location, and quantification of damage to structural layers throughout the structure's mission. This capability must be accomplished within real constraints for sensor volume, mass, and crew resources, including being able to perform effective NDE of the inflatable habitat layers from the interior during a mission either on a routine basis or as a quickresponse basis. 


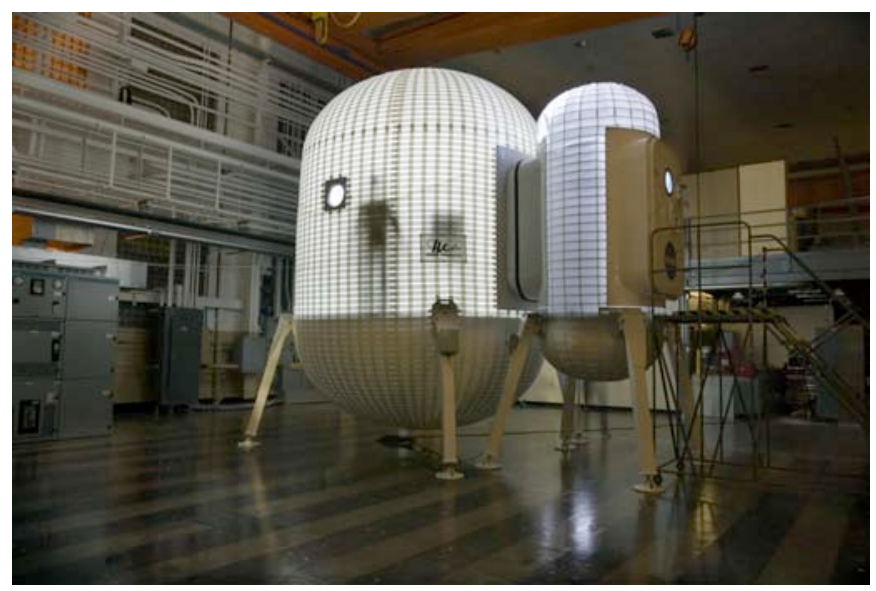

Figure 1. A model of one concept of an inflatable habitat module for use on the moon.

A test article was built that exhibited the general features of an inflatable habitat module wall. Damage to various layers was induced. This effort was then followed by a series of NDE tests to evaluate the ability of NDE to detect the damage. Damages of interest were MMOD damage to the outer layers, damage to the structural layer that maintains the module's wall shape and structural integrity, and damage to the interior layers that confine the interior atmosphere. This study will help NASA to focus on technologies which might be further developed for possible application to space missions.

\section{TEST ARTICLES}

Figure 2 shows the generalized structure of an inflatable habitat module. The basic structure of MMOD shielding is an exterior layer of Multi-Layer Insulation (MLI) and three groups of fabric layers. In this example, the layers were made up of either fiberglass or Kevlar. These groups of layers would be separated by low density foam. Inside the MMOD shielding is a structural restraint layer made of woven Kevlar belts or straps. Inside the restraint layer is a series of felt layers and bladder layers. On the inside is a final layer that provides scuff and fire protection to the habitat module.

Figure 3 shows two photographs of the inflatable habitat module wall test article that was used for these tests. Panel (a) shows the interior wall side of the test article. Panel (b) shows the exterior layers. Each of the MMOD shielding layers was clamped separately within one of three frames, which were then bolted together. The interior layers were also clamped into the third frame. This test article was then exposed to five hypervelocity impacts (five different sized projectiles shot at approximately $7 \mathrm{Km} / \mathrm{s}$ ) to simulate MMOD damage. The locations of the five impacts can be seen in Fig. $3 \mathrm{~b}$ as faint "+" marks on the outer layer wall.

Figure 4 shows a series of photographs that document the hypervelocity impact damage. All of the impacts were predicted to penetrate no further than the third MMOD shield layer. The five impact locations are visible in Figure 4a on the outer layer as small perforations. Fig. $4 \mathrm{~b}$ shows the obverse side where the damage is highlighted by a spray of debris on the larger three impacts. Fig. 4c is the impact side of the middle MMOD shield. The debris spray from the impacts again highlights the five impact sites. Fig. 4d shows the obverse side of the middle MMOD shield. The two impact sites at the top of the target did not penetrate through the second layer, while the other three sites show damage. Fig. $4 \mathrm{e}$ 


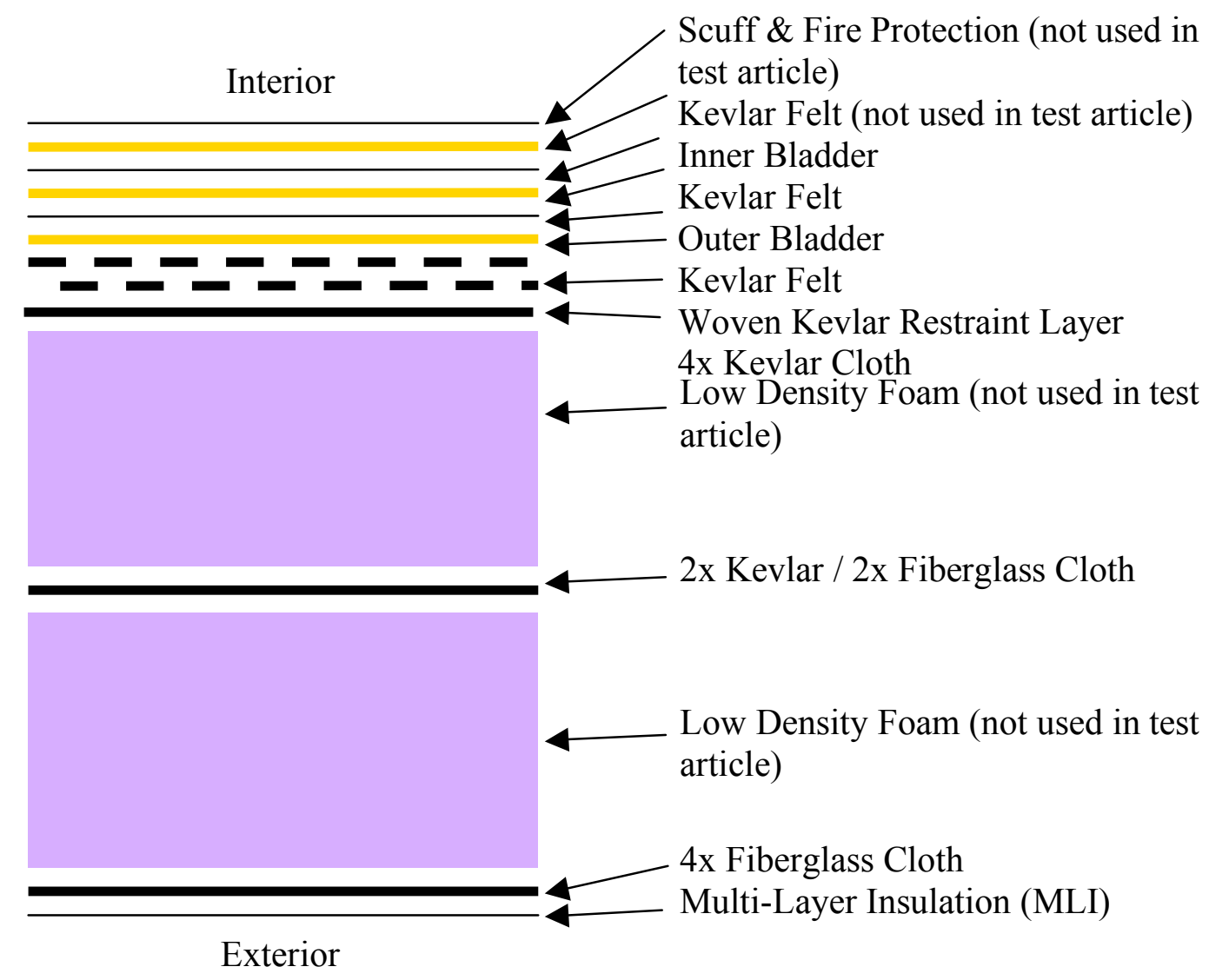

Figure 2. A baseline inflatable habitat module wall structure. Some of the layers that were omitted in the test article are noted.

shows the inner layer where three impacts penetrated. Fig. 4f shows the inner layer's obverse side where no impact damage is readily visible. In fact, there is a region in the center where there is a small amount of damage to the fabric. Fig. 4g shows the Kevlar restraint layer. There was no impact damage to the restraint layer. Fig. 4h shows the combined interior surface layers.

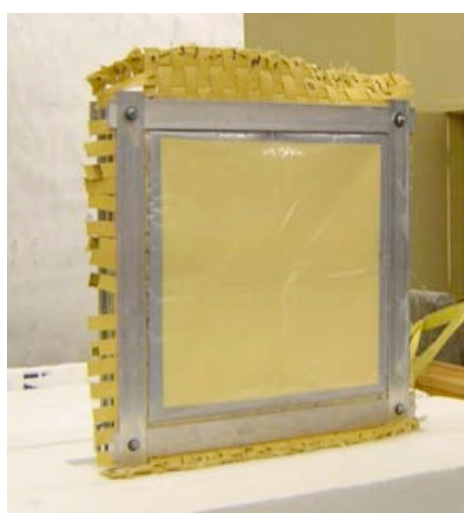

(a)

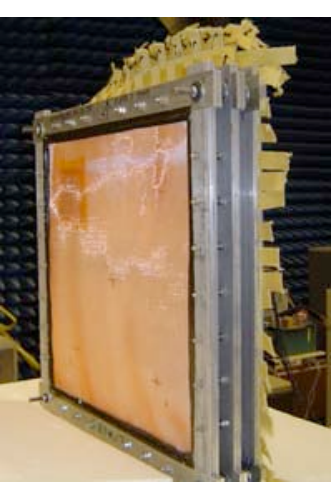

(b)

Figure 3. Photographs of the inflatable habitat module wall test article that was used for these tests. Panel (a) shows the interior wall side of the test article. Panel (b) shows the exterior layers. The three MMOD shielding layers were clamped separately by the three frame elements seen in the photograph. The copper screen layer, which is visible in the photo, was only used during microwave NDE testing to provide a reflecting surface. 
(a)

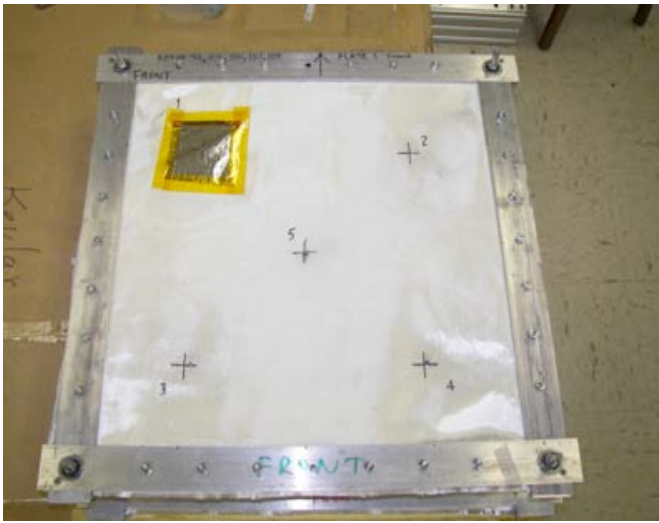

(c)

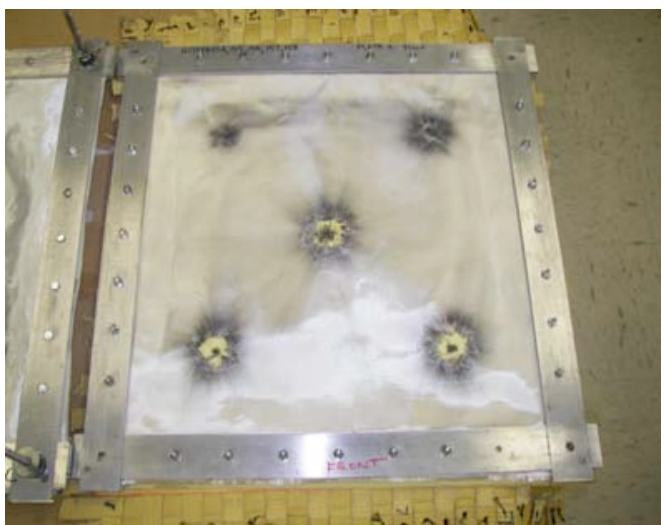

(d)

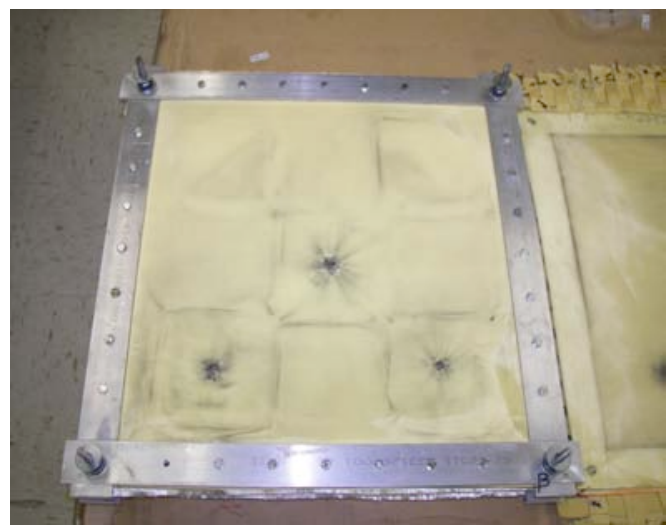

(e)

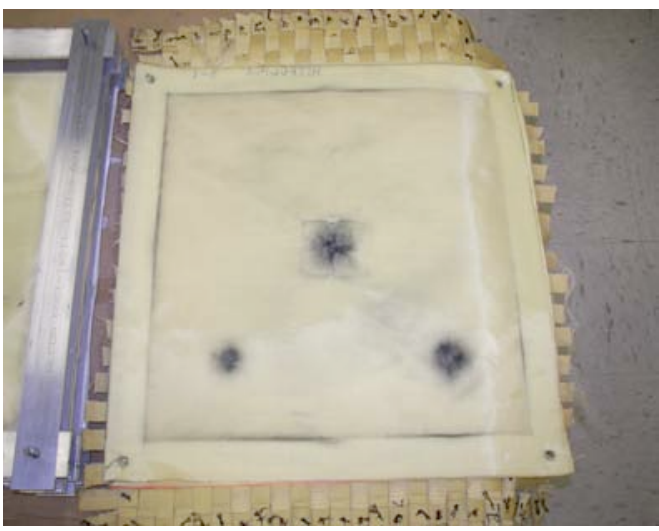

(f)

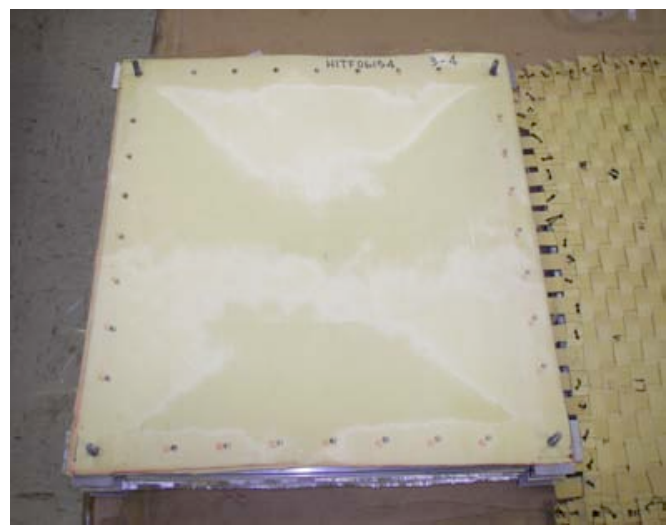

(h)

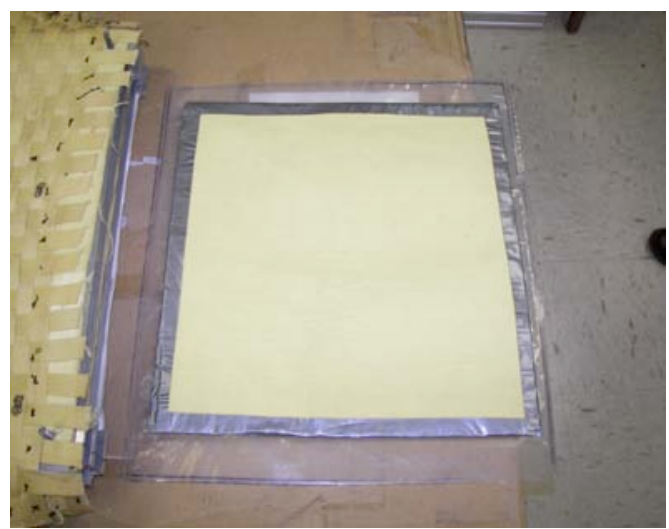

Figure 4. The various layers of the test article. (a) and (b): Front and back of the outer MMOD shield. (c) and (d): Front and back of the middle MMOD layer. (e) and (f): Front and back of the inner MMOD layer. (g) The Kevlar restraint layer. (h) The interior layers. 
To test damage in the Kevlar belts of the restraint layer, one belt was removed and replaced by a second belt that had been damaged by being cut and from having holes drilled, burned, and punched through the fabric. This belt was rewoven into the restraint layer for later testing. To test damage for the inner layer, a small piece of plastic, similar to the bladder layer, had several holes punched through it. The layer was then inserted into the inside of the multilayer surface layer.

\section{RESULTS}

The prime candidates for evaluating this test article were electromagnetic methods. Methods such as ultrasound and thermography were expected to be ineffective given the layered nature of this test article. Testing verified that both ultrasound and thermography methods performed poorly. Several materials, such as Kevlar belts, Kevlar and fiberglass fabrics, and Kevlar felts were tested to understand their electromagnetic attenuation and velocity dispersion. The measurements ranged from as low as $15 \mathrm{GHz}$ to as high as 10 $\mathrm{THz}$ and were performed at Sandia National Labs (DOE) [3], Pacific Northwest National Labs (DOE) [4], and NASA Langley Research Center [5]. Figure 5 shows some of the attenuation values measured for Kevlar fabric materials. For the frequencies above $1 \mathrm{THz}$, the attenuation continued to increase until little radiation could penetrate. The low frequency attenuation measurements were made at 15 and $33 \mathrm{GHz}$ where the attenuation was $0.09 \mathrm{~dB}$ and $0.80 \mathrm{~dB}$ respectively.

A microwave imaging system with a circularly polarized transceiver was used to measure this habitat wall sample in the frequency range of 10 to $20 \mathrm{GHz}$. The measurements were made at the Pacific Northwest National Lab (DOE) [6]. The transceiver was set at $0.72 \mathrm{~m}$ from the sample and was scanned both horizontally and vertically to form a synthetic aperture data array of $1 \mathrm{x} 1$ meter dimensions. The resolution was expected to be approximately $1.5 \mathrm{~cm}$ in range and $0.75 \mathrm{~cm}$ in cross-range. Figure 6 shows results of the scan made of the test article at 10 to $20 \mathrm{GHz}$. The images represent data focused on the back MMOD shield layer, which had a copper screen that acted as a strong reflector. Fig. 6a represents an image made with right circularly polarized (R) transmitted microwaves and left circularly polarized $(\mathrm{L})$ received microwaves. This image

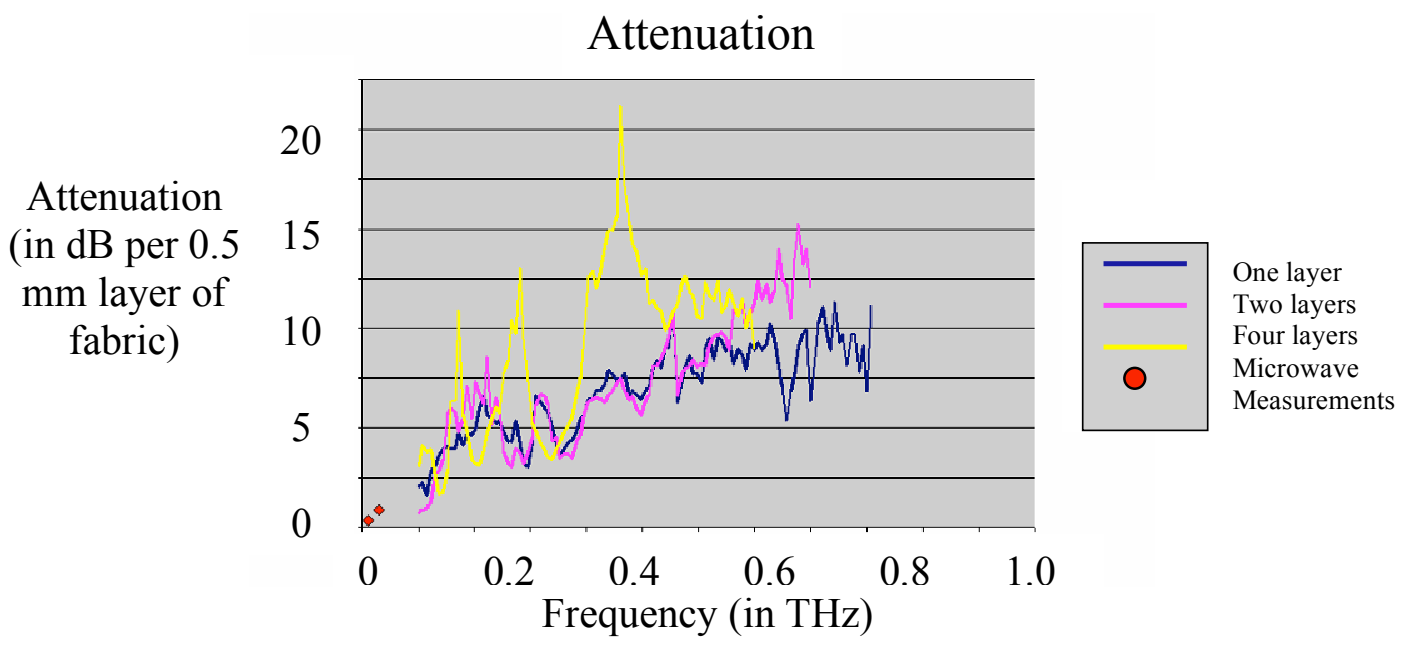

Figure 5. The electromagnetic attenuation of Kevlar fabric materials from $15 \mathrm{GHz}$ to 0.8 THz. The low frequency radar measurements are shown as circles near the lower left axis. 


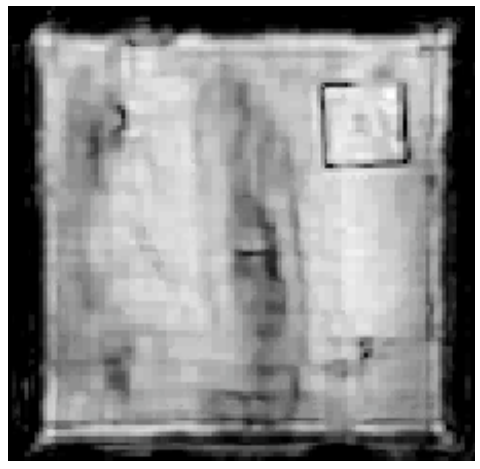

(a)

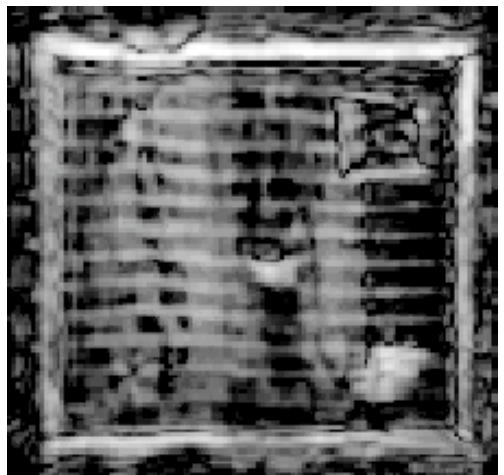

(b)

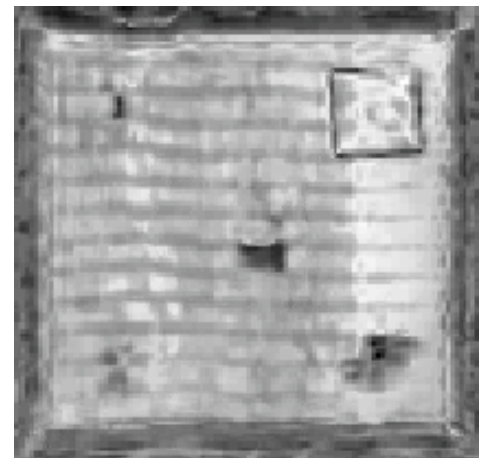

(c)

Fig. 6. 10-20 GHz Microwave images of the outer MMOD shield layer. (a) Image represents a R-L polarized image. (b) Image represents a R-R polarized image. (c) Image represents the difference image between (a) and (b).

represents microwaves that are directly reflected from the target. Fig. $6 \mathrm{~b}$ is an image made with R-R polarized microwaves on transmit and received, which represents indirect or multiple reflections. Fig $6 \mathrm{c}$ is a difference image made from Fig. $6 \mathrm{a}$ and $6 \mathrm{~b}$. The five impact damaged regions at the back layer are visible. The difference image helped to remove some of the artifacts caused by the unevenness of the layers. All the images show some effects from the overlying layers, including the Kevlar restraint layer.

A millimeter wave imaging system with a linearly polarized transceiver located at the Pacific Northwest National Lab (DOE) was used to measure this habitat wall sample in the frequency range of 40 to $60 \mathrm{GHz}$ [4]. The transceiver was positioned $0.44 \mathrm{~m}$ from the sample and was scanned horizontally and vertically to form a synthetic aperture data array of $1 \mathrm{x} 1$ meter dimensions. The resolution for this frequency range was expected to have a resolution of approximately $7.5 \mathrm{~mm}$ in range and $1.5 \mathrm{~mm}$ in cross-range. The resulting millimeter wave images are shown in Figure 7. These images were made with a horizontally polarized transmitter and receiver operating in the frequency range of 40 to 60 $\mathrm{GHz}$ and focused on different layers. The image in Figure 7a was generated when focus was at the outer MMOD shield layer and the image in Figure $7 \mathrm{~b}$ was generated when focus was at the interior MMOD shield layer plus the Kevlar restraint layer. The five impacts are still detectable at the outer wall, although the restraint layer's effects are becoming more evident at the higher resolution. The image in Figure $7 \mathrm{~b}$ shows the web pattern of the restraint layer. At this focal distance and frequency, the image shows more detail of the Kevlar restraint layer.

Two regions of the habitat module that are of the more concern are the interior layers of the Kevlar restraint layer and the bladder layers. The integrity of the structure depends on the Kevlar restraint layer. This layer is under a significant level of stress at atmospheric pressure. Significant damage to this layer, which is not visible from the interior, could lead to rupture of the wall. In addition, the integrity of the bladder layers is important, as even a small breech in those layers will allow the loss of air from the module. The terahertz imaging system at NASA Langley Research Center, which operates in the $100 \mathrm{GHz}$ to 2 $\mathrm{THz}$ frequency range, was used to scan these layers. For these scans, the layers were placed under a plastic sheet and the air was evacuated to produce an atmosphere pressure difference against the wall to simulate the wall being under pressure and compression. Fig. 8 a shows a photograph of the scan setup with the wall being compressed. Fig. $8 \mathrm{~b}$ shows an image of the scanned region. In the scan image of Fig. $8 \mathrm{~b}$ the warp and welt weaving of the Kevlar are well resolved. It is evident that there is a transition in the Kevlar layer on the 


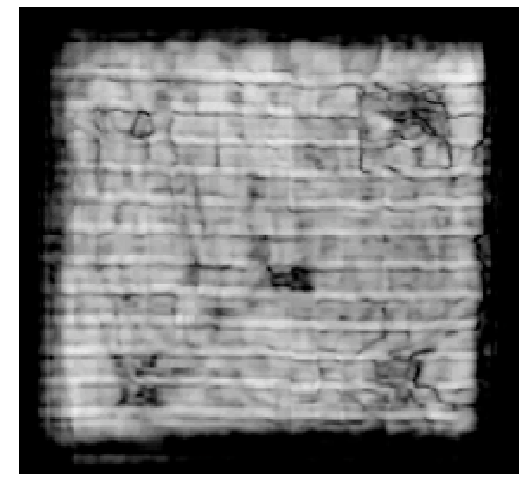

(a)

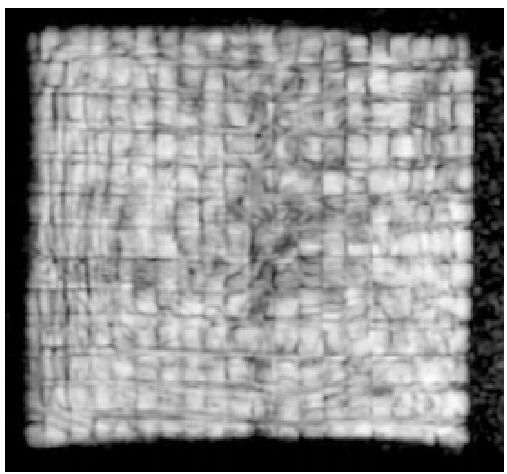

(b)

Fig. 7. 40-60 GHz millimeter wave images of the target layers. (a) Image represents an H$\mathrm{H}$ linearly polarized image of the outer MMOD shield. (b) Image represents an $\mathrm{H}-\mathrm{H}$ polarized image of the interior MMOD shield with the Kevlar restraint layer.

right side of the image. This transition results from the use of thinner Kevlar belts $(0.035$ " thick vs. 0.090" thick).

To investigate the capability of the system to detect damage in the Kevlar belts, one of the warp belts was extracted and another belt with holes and cuts was reinstalled. Fig. 9a shows a photograph of the damaged belt. Fig. 9b shows the results of scanning that belt within the restraint layer. The cuts on the edge are evident in the image as mars on the side of the belt in the image. The holes did not produce large contrast, but they were detectable as dark spots in the image. Fig. 9c shows an image where plastic material similar to the bladder material was inserted in between the front layers. This layer had numerous holes punched through the plastic. The holes in this material are easily detected in the image.

\section{CONCLUSION}

As NASA investigates the development of inflatable habitat structures for potential orbital, transfer, and planetary applications, NDE methods are also being evaluated. The ultimate goal is to develop NDE methods that have the ability to perform detection, loca-

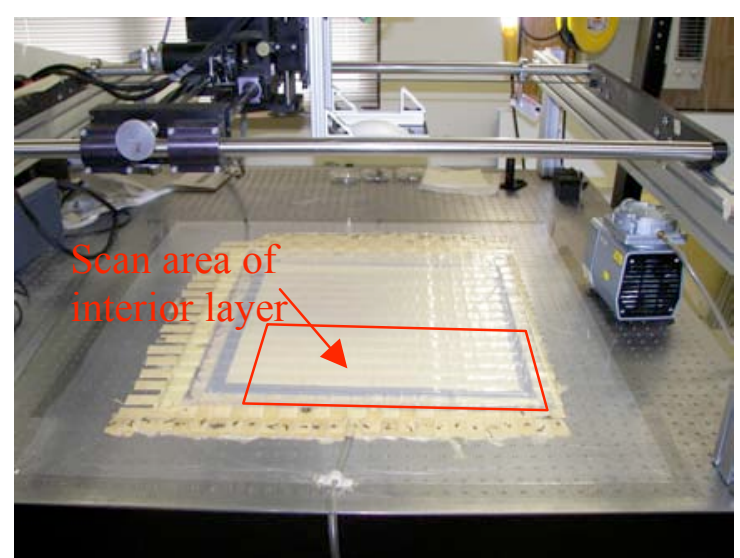

(a)

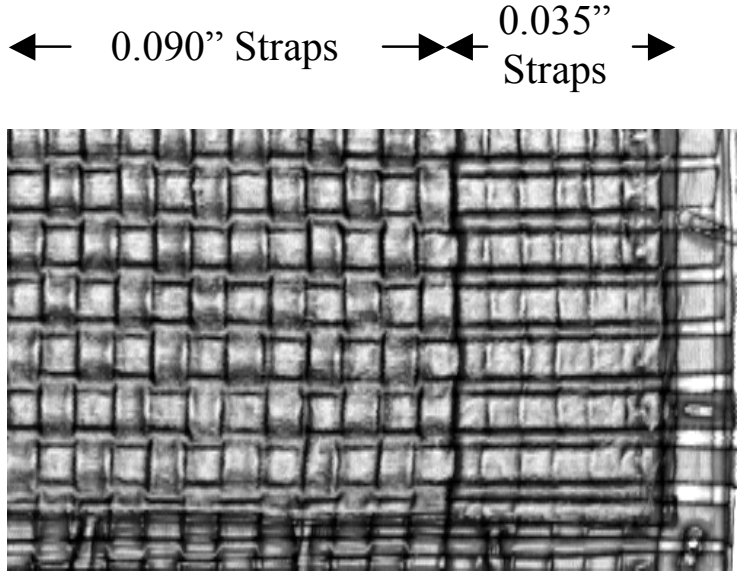

(b)

Figure 8. (a) Photograph of the terahertz scanning system at NASA Langley Research Center with the Kevlar restraint layer and the interior wall layers in place for scanning. (b) A terahertz scan of the interior layers. 
(a)

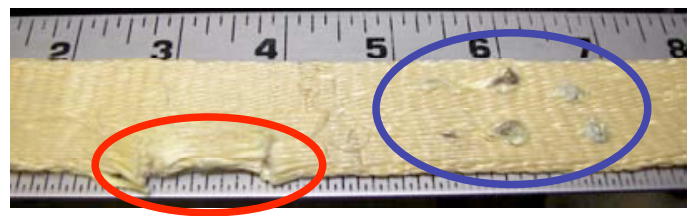

(b)

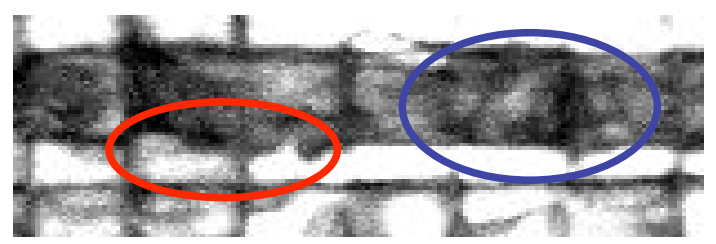

(c)

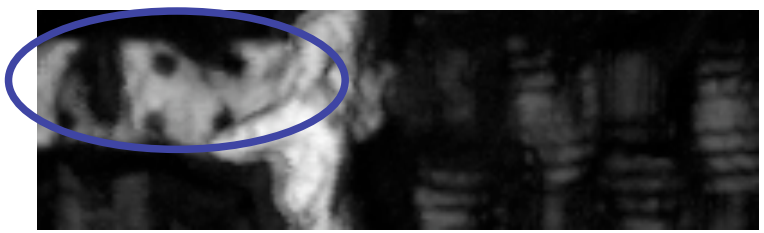

Figure 9. (a) A photograph of a Kevlar belt with induced damage (circled). (b) Scan image of the belt after it was reinserted into the restraint layer showing the damaged regions (circled). (c) Scan image of damaged bladder material inserted into the front layer (circled).

tion, and quantification of damage to structural layers during the structure's mission, within real constraints for sensor volume, mass, and crew resources.

This project illustrated that several electromagnetic radiations wavelengths were effective in imaging the inflatable habitat walls. Microwave imaging was able to detect hypervelocity impact damage at the outer wall. Millimeter wave imaging was able to image the back wall and the inner walls. Terahertz imaging was used to focus on imaging the restraint layers and the interior bladder layers. Terahertz imaging demonstrated the ability to detect small cuts and holes in the Kevlar restraint layer as well as small holes in the plastic bladder layer. Future work will be directed toward developing these imaging modalities for space operations.

\section{REFERENCES}

1. E. J. Brandon, et. al., "Structural Health System Technologies for Inflatable/Deployable Space Vehicles", NASA Exploration Systems Mission Directorate Final Report, Sept. 24, 2006.

2. G. F. Studor, E. I. Madaras, W. P. Winfree, R. O Nellums, and D. L. McMakin, "Insitu Damage Imaging of Inflatable Structures", Internal Project Report, March 14, 2007

3. M. Wanke and M. Lee, "Transmission Measurements on Moon Base Materials", Sandia National Laboratories, Internal Project Report, 2006.

4. D. McMakin and R. Severtsen, "Additional In-situ MMOD Damage Imaging and Attenuation Results", Pacific Northwest National Laboratory, Internal Project Report, Nov. 29, 2007.

5. E. I. Madaras, "Terahertz Results for Three Habitat Module Fabrics", NASA Langley Research Center, Internal Project Report, 2006.

6. D. McMakin and R. Severtsen, "In-situ MMOD Damage Imaging", Pacific Northwest National Laboratory, Internal Project Report, July 7, 2006. 


\title{
The Potential for Imaging of In Situ Damage in Inflatable Space Structures
}

\author{
Eric I. Madaras \\ Nondestructive Evaluation Sciences Branch \\ NASA Langley Research Center \\ Hampton, VA 23681
}

34th Annual Review of Progress in Quantitative NDE,

July 22-27, 2007

Golden, Colorado

Sandia is a multiprogram laboratory operated by Sandia Corporation, a Lockheed Martin Company,

for the United States Department of Energy's National Nuclear Security Administration under contract DE-AC04-94AL85000.

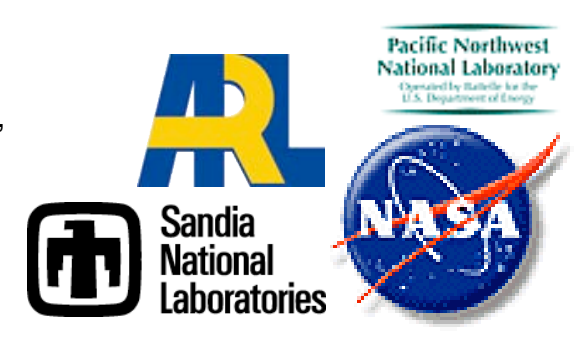




\section{Research Team}

Eric I. Madaras, William P. Winfree, Elliott Cramer

NASA Langley Research Center, Nondestructive Evaluation Sciences Branch, MS 231 Hampton, VA 23681

Robert F. Anastasi

U.S. Army Research Laboratory, Vehicle Technology Directorate, AMSRD-ARL-VT-SM, Nondestructive

Evaluation Sciences Branch, NASA Langley Research Center, MS 231, Hampton, VA 23681

Jeffrey P. Seebo

Lockheed Martin, NASA Langley Research Center, MS 231, Hampton, VA 23681

George Studor

NASA Johnson Space Center, Structures Branch, ES2, Houston, TX

Douglas L. McMakin

Pacific Northwest National Laboratory, Applied Physics, P.O. Box 999 MSIN:K2-31, Richland, WA, 99354

Robert Nellums

Sandia National Laboratory, P.O. Box 5800, Albuquerque, N.M. 87185 


\section{Inflatable Habitat Concepts for Orbital, Transfer, and Planetary Applications}

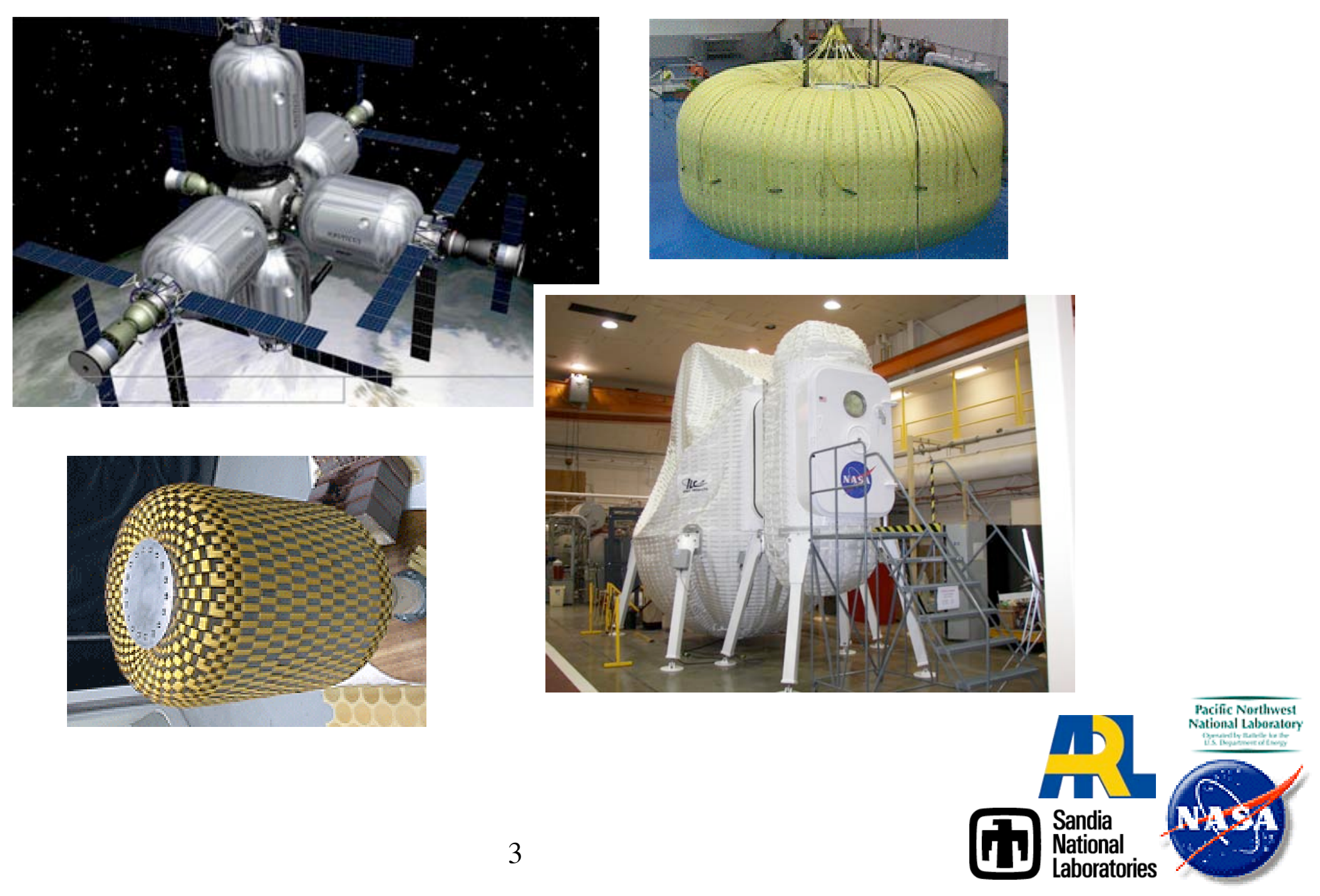




\section{Inflatable Habitat Structures for Orbital, Transfer, and Planetary Applications}

- Inflatable habitat structures have significant potential for NASA's long duration missions being planned for the coming decades.

- All space related structures are vulnerable to damage from micrometeoroid and orbital debris (MMOD).

- The ability to monitor and assess structural health is an important factor in determining the feasibility of using inflatable technologies for habitat requirements.

- Performing effective nondestructive evaluation (NDE) of the inflatable habitat layers from the interior during a mission either on a routine basis or as quick-response basis is a capability which, if developed, could be attractive for long duration space missions. 


\section{Damage and Leaks: Risk vs Decision Time vs Effort vs Effectiveness}

- Conditions:

- No leaks, but structural damage. Possible actions:

- Do nothing or repair?

- Inspect and document?

- Monitor overtime?

- Small leaks-Possible actions:

- Locate and inspect?

- Plug or don't plug?

- Monitor overtime?

- Moderate leaks-

- Required response: Attempt to repair or plug (Interior or Exterior).

- Possible actions:

- Inspect and document?

- Recertification. Is structural integrity maintained? Is repair adequate?

- Severe leaks-

- Required response: Evacuate module.

- Additional possible actions

- Is there any possibility to repressurize?

- Repair by exterior means? (Can the rupture be located from the outside?)

- Structural recertification?

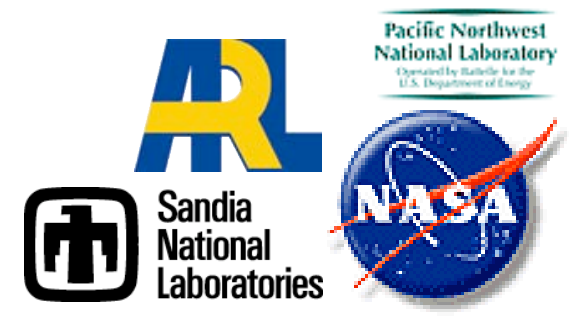




\section{Objective}

- Examine the feasibility of inspecting inflatable structures with various NDE technologies

- Help down select which technologies might be further developed for possible application to space missions.

\section{Approach}

- Exposed an inflatable habitat wall mockup to hypervelocity impacts.

- Image damage with NDE technologies. 


\section{Baseline Tested Wall Structure}

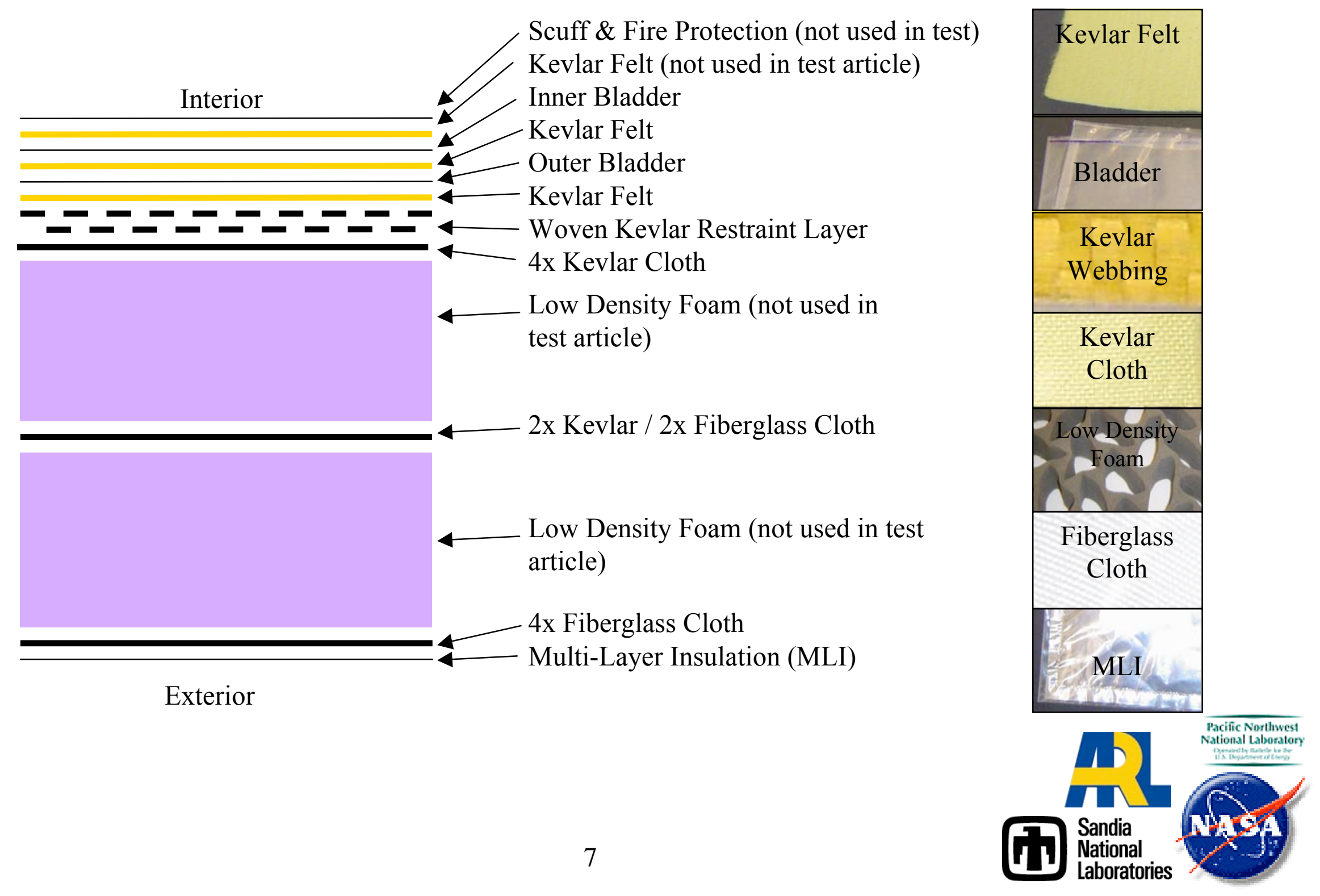




\section{Baseline Wall Structure}

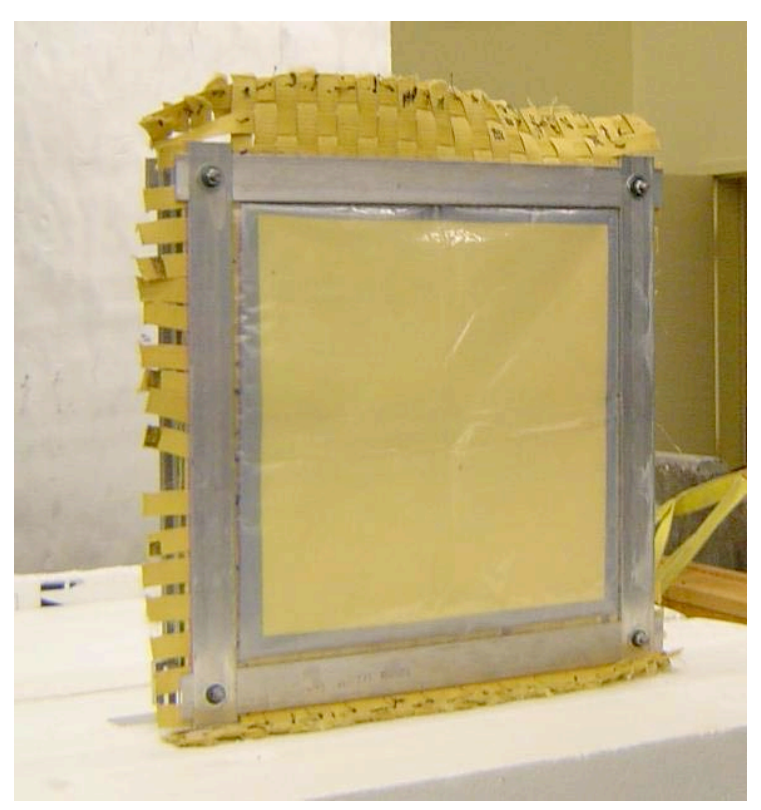

Front view of impact sample (Interior side)

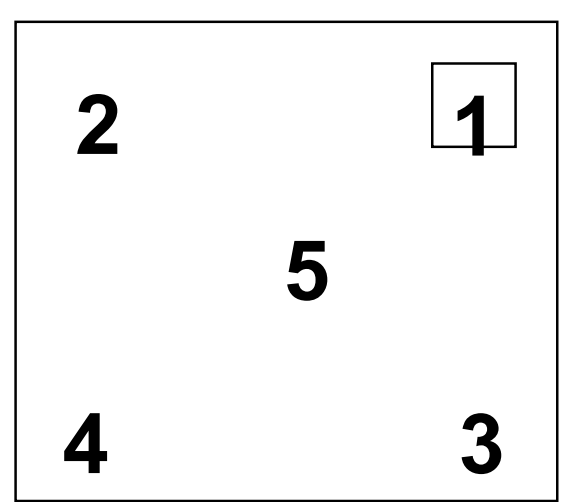

MMOD shot pattern (Interior view)

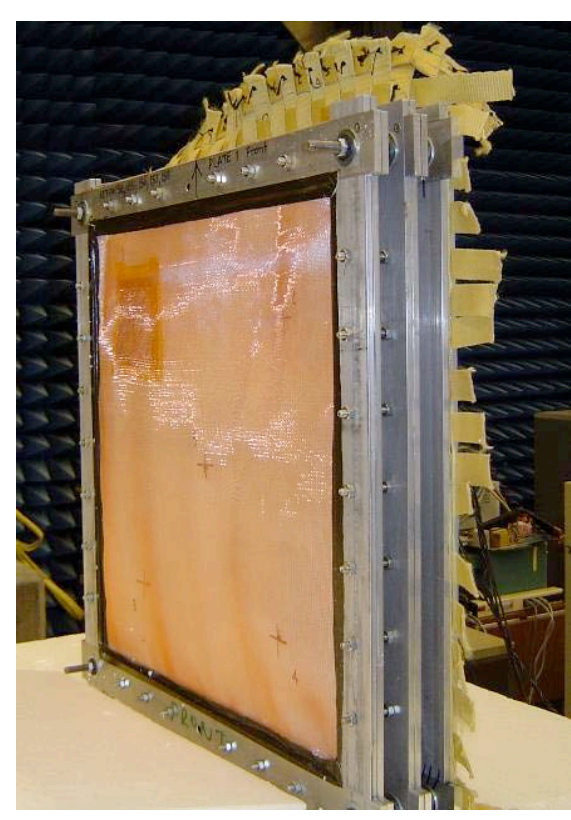

Back view of impact sample (Exterior side)

Impact goal was to only damage the MMOD layers and not the webbing and interior layers. 


\section{Impact Damage}
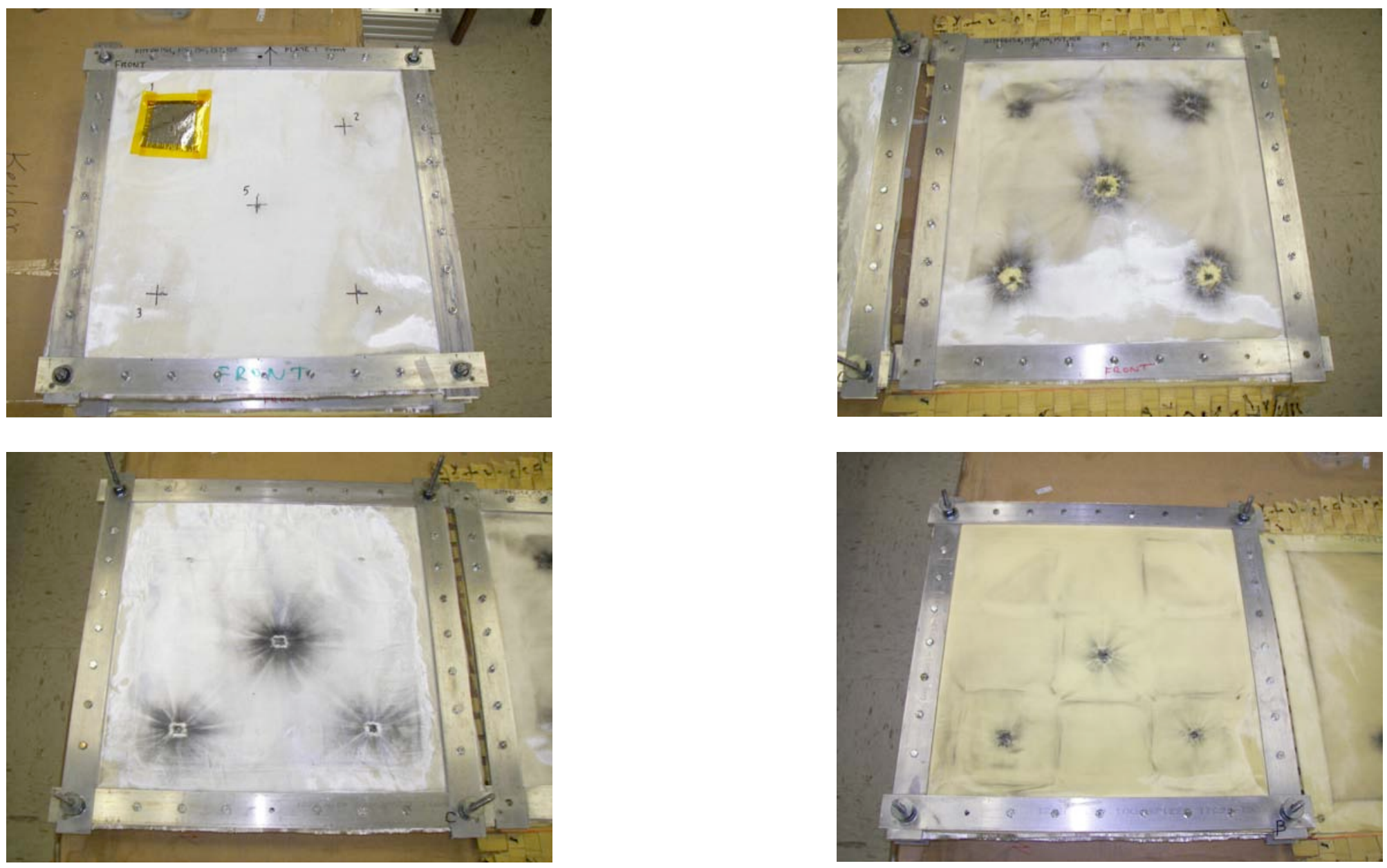

Exterior layers

Top Image: Outside Bottom Image: Obverse

Middle layers

Parific Northest Top: Outside (1) Bottom: Obverse 


\section{Impact Damage}
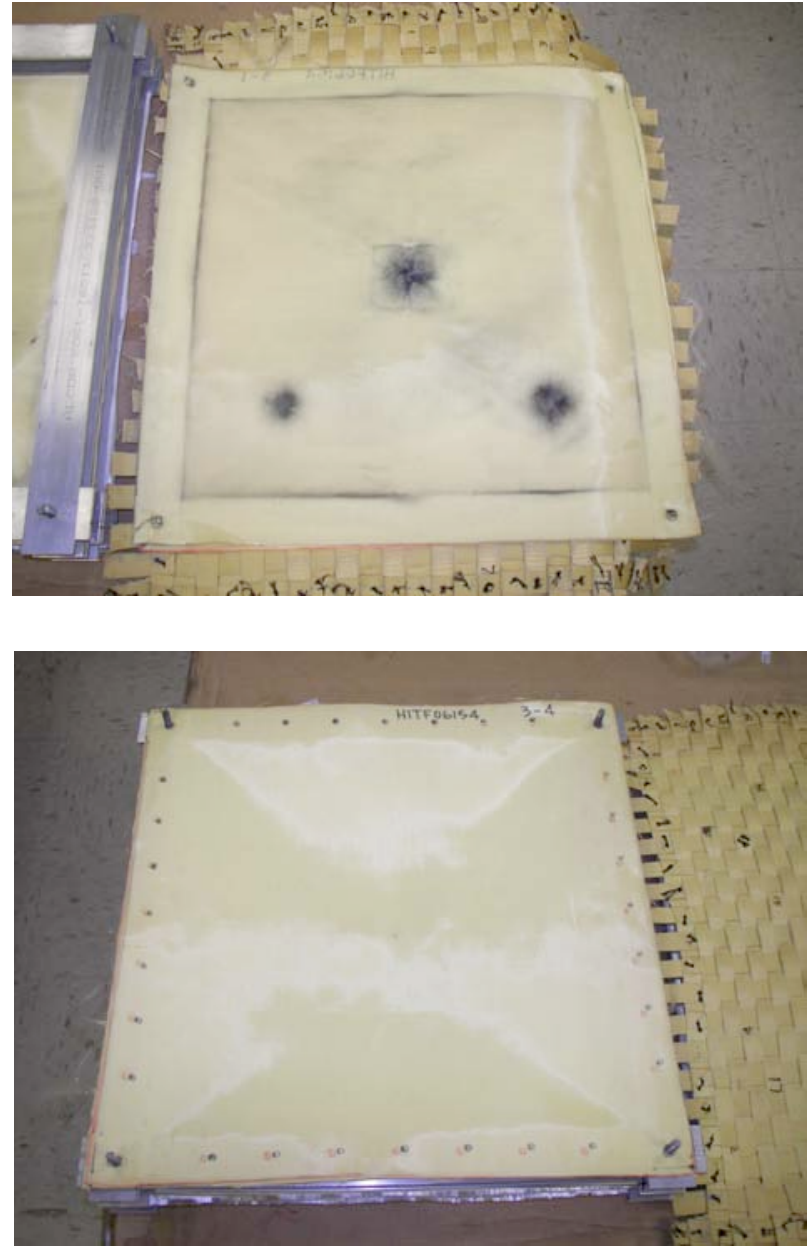

Interior layers (w/MMOD damage)

Top: Backside of wall

Bottom: Inside of shield fabrics
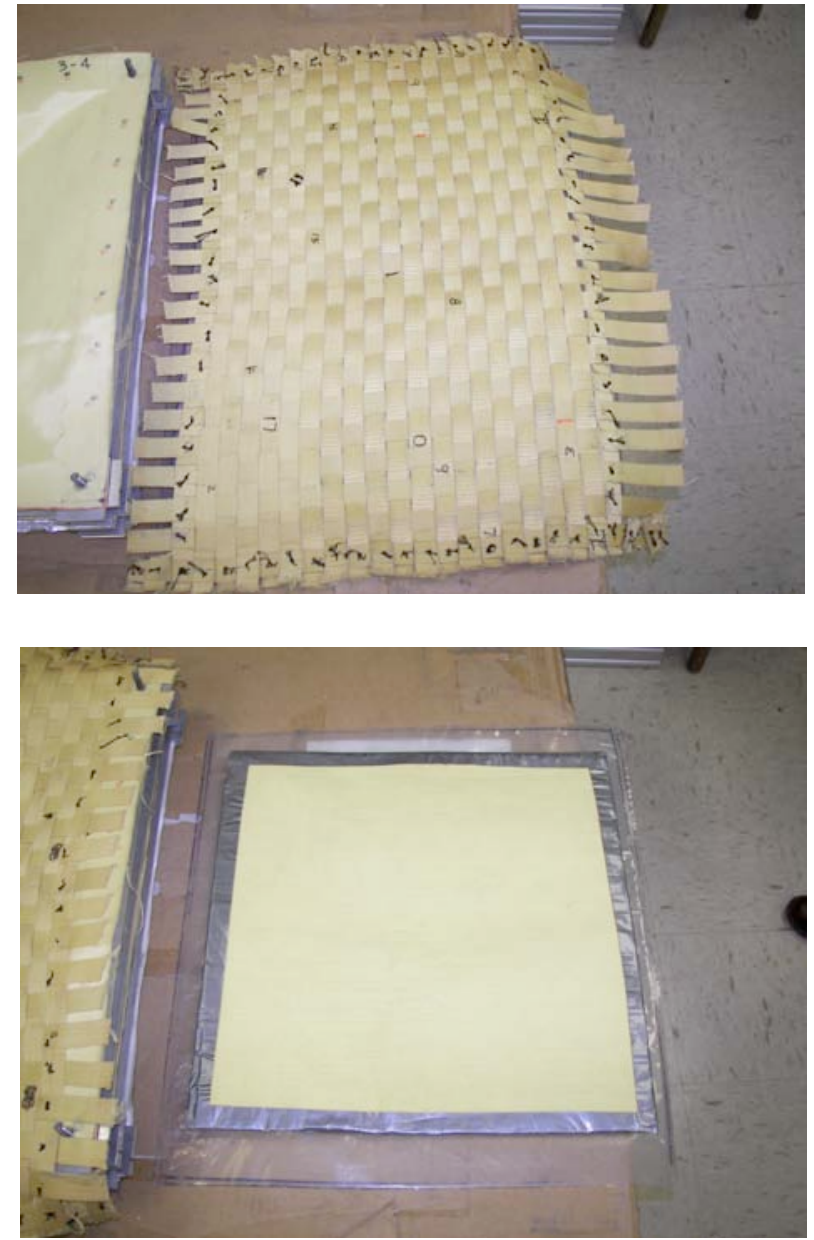

Interior layers (No MMOD damage) Top: Structural Kevlar webbing Bottom: Inside of wall 


\section{Potential of Thermography and Ultrasound}

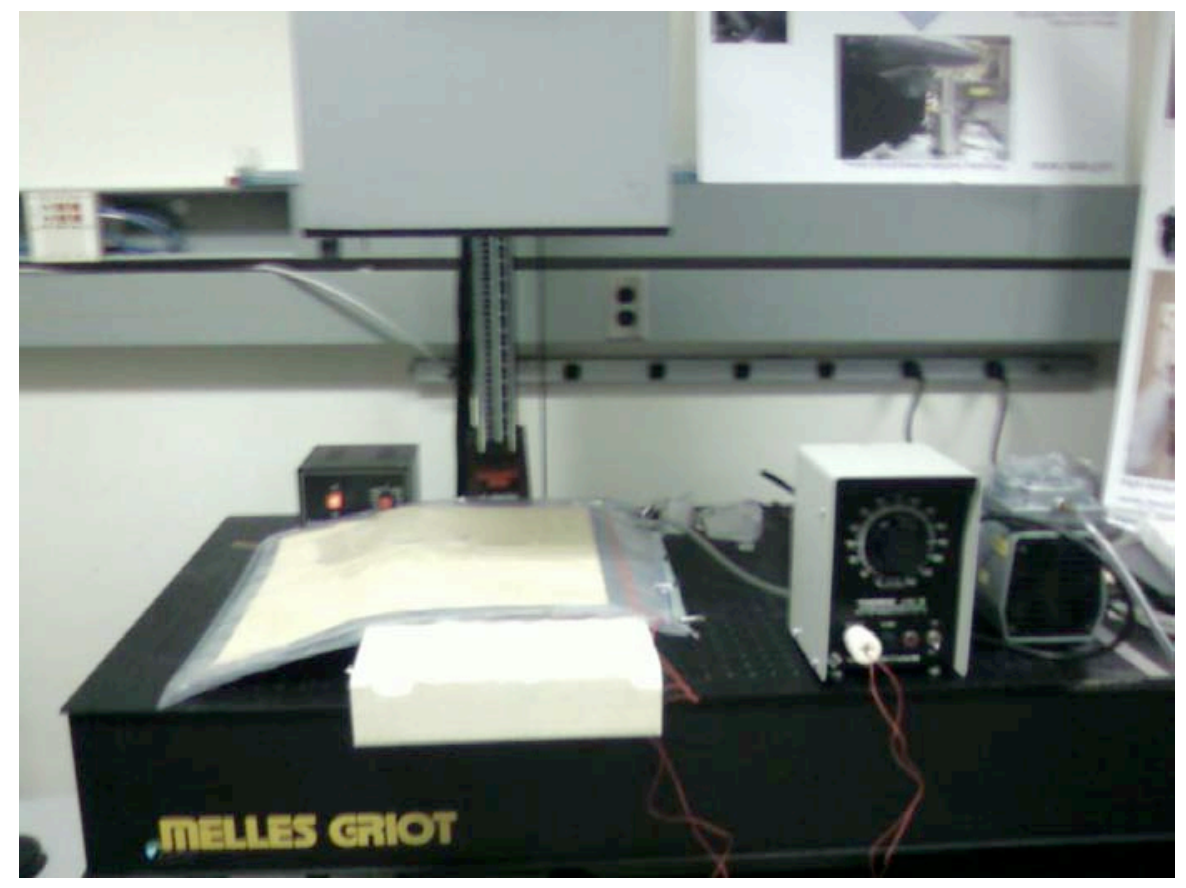

- Thru transmission thermography measurements

- Thin polyethylene insert with holes

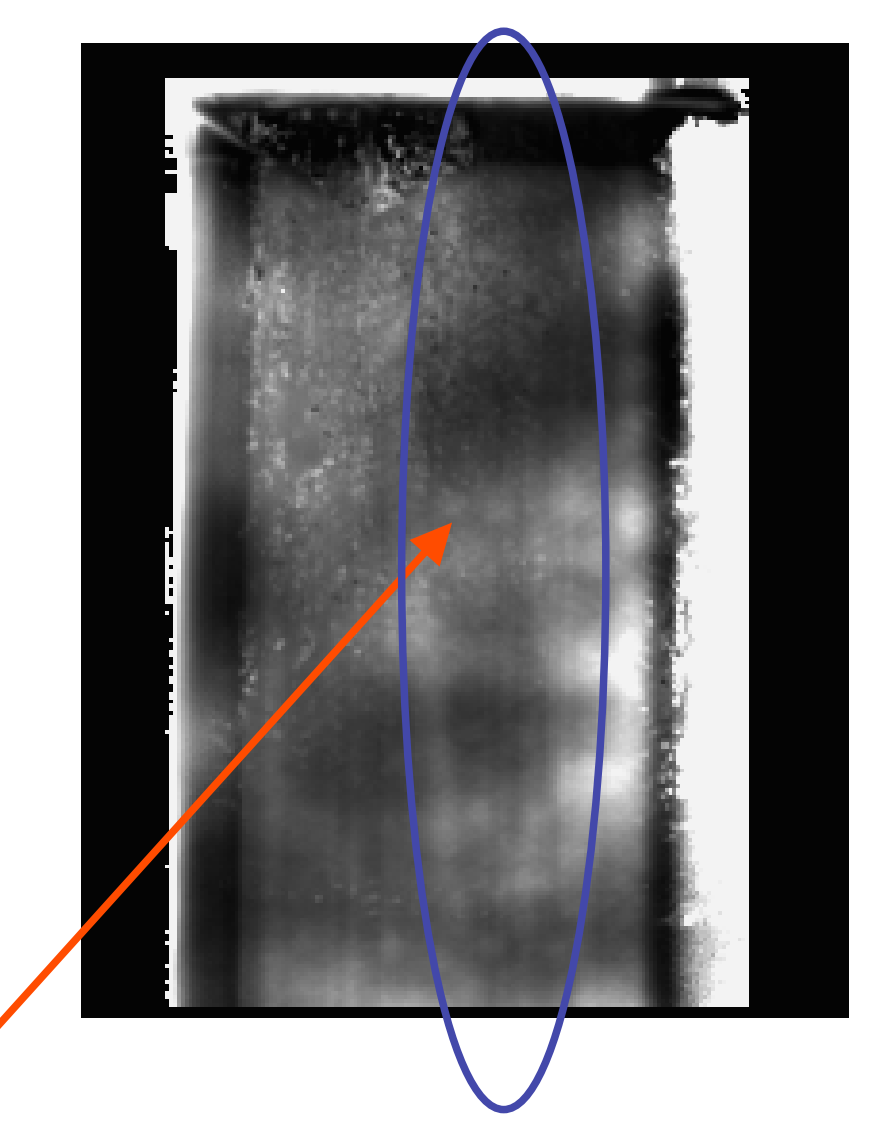
slightly visible with through thickness heating, but damage in Kevlar webbing was not detectable

- Ultrasound was too attenuative across the numerous interior layers to produce an image

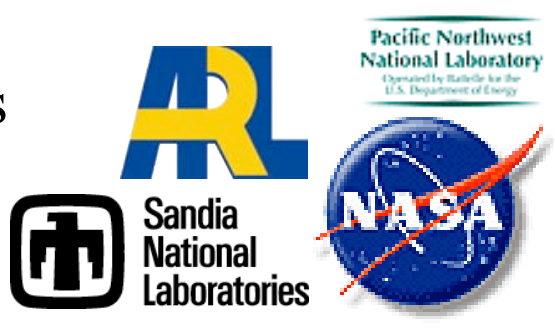




\section{Electromagnetic Response Measurements for Kevlar Webbing}
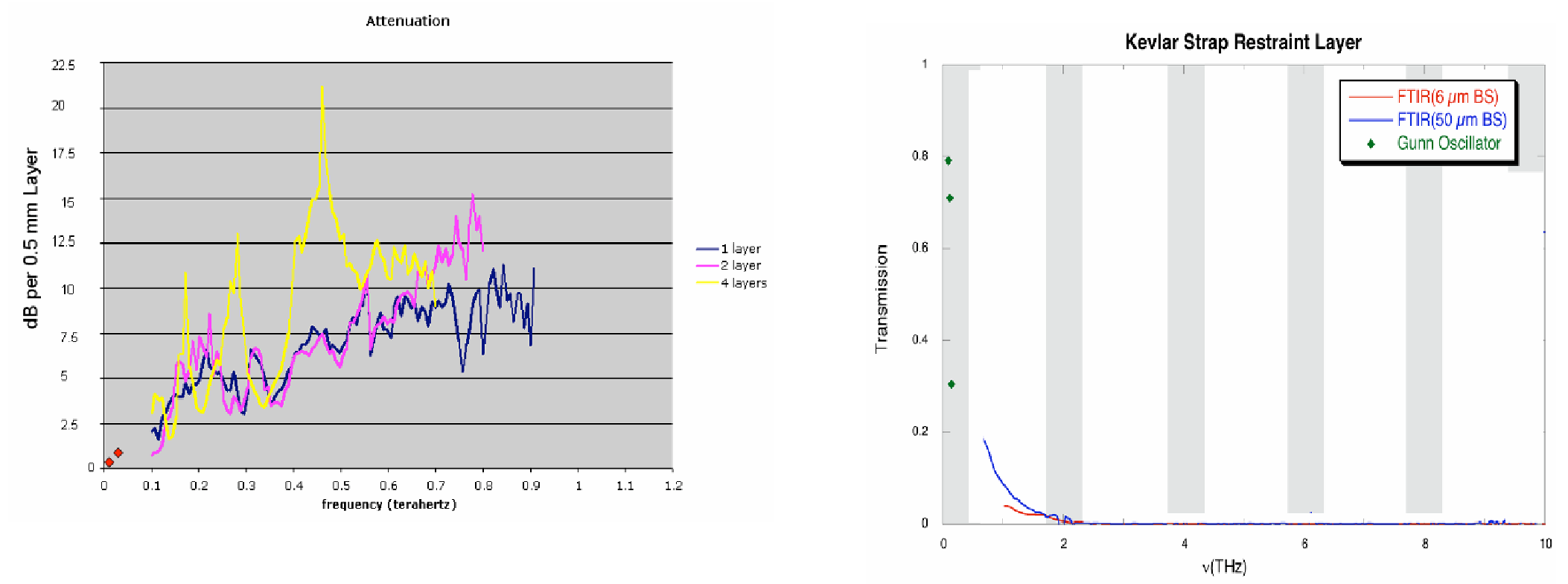

- At left are attenuation results for Kevlar Web, 0.1-0.9 THz. (NASA LaRC).

- Loss measurements for 15 and $33 \mathrm{GHz}$ were $0.09 \mathrm{~dB}$ and $0.80 \mathrm{~dB}$ respectively, and shown as red diamonds in plot at left. (PNNL).

- At right are transmission results for the Kevlar Web, 0.7-10 THz (SNL).

- All of the following tests were made with reflection measurements. 


\section{Microwaves $10-20 \mathrm{GHz}$}

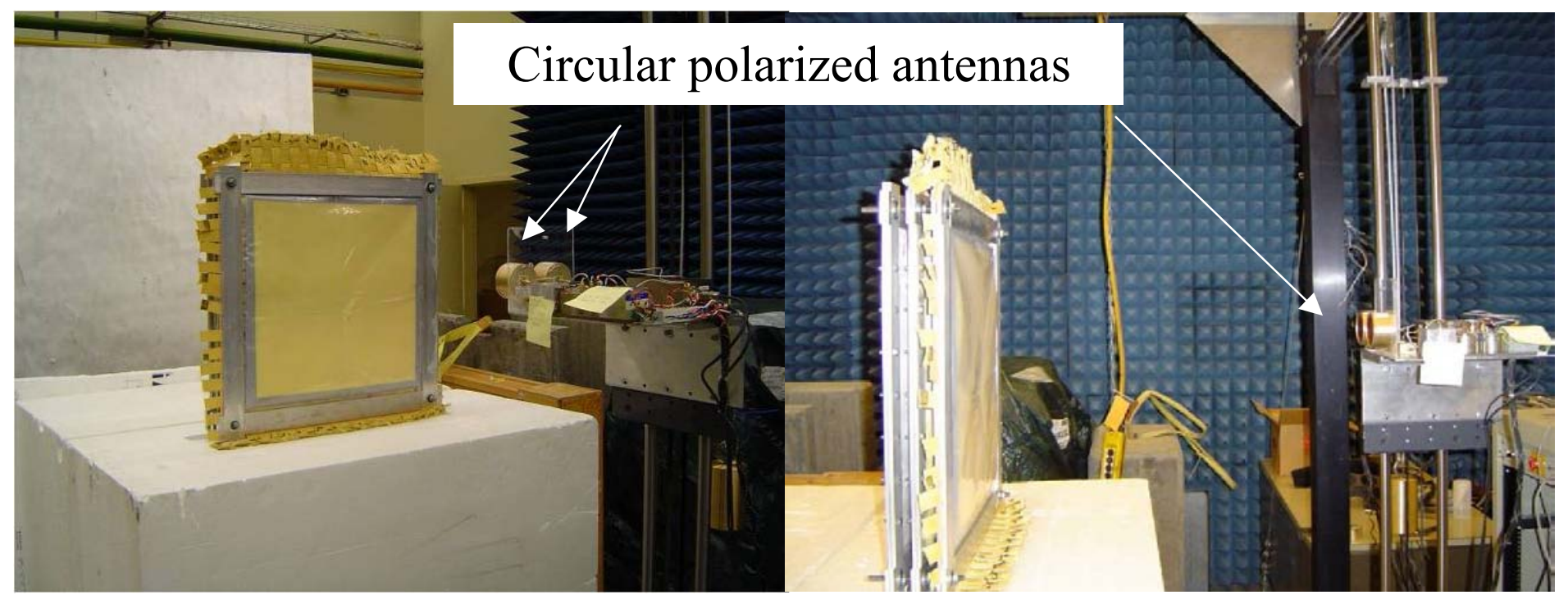

- Measurements were performed at Pacific Northwest National Labs

- Circularly polarized transceiver with a frequency range of $10-20 \mathrm{GHz}$

- 0.72 meter standoff.

- The transceiver was scanned horizontally and vertically to form a synthetic aperture of $1 \times 1$ meter dimension.

- Expected resolution is approximately $1.5 \mathrm{~cm}$ in range and $1.0 \mathrm{~cm}$ in cross-range. 


\section{0-20 GHz Images of Exterior Damage}
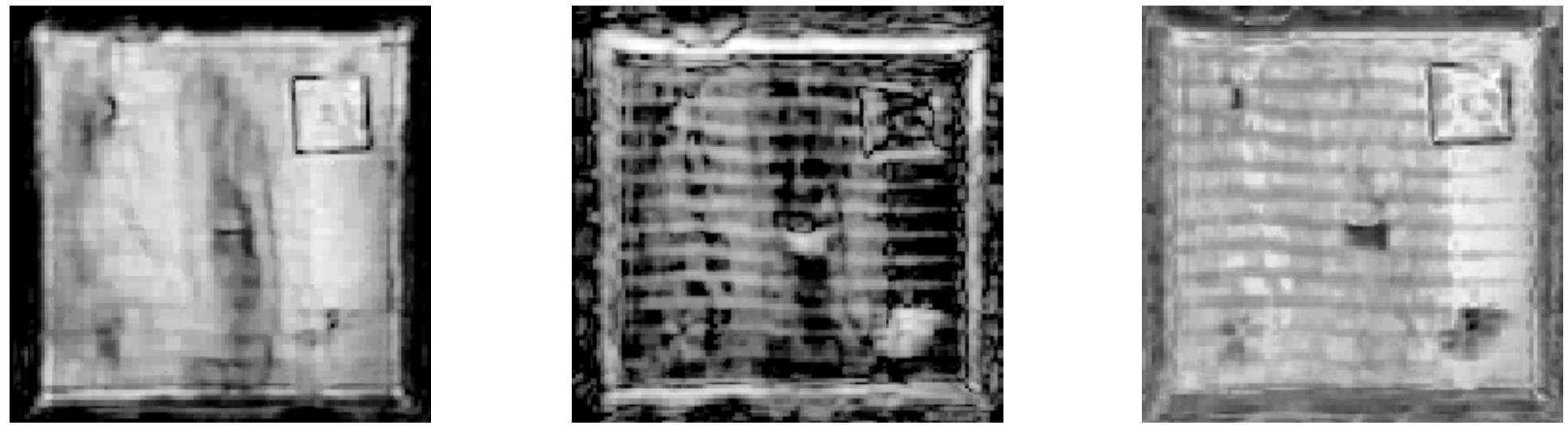

- $10-20 \mathrm{GHz}$ images of damaged region of test target, nearest the outside layer of MLI and copper screen.

- The image at left is R-L polarization associated with direct return.

- The image at center is R-R polarization associated with multiple scattering. The image at right is difference. 


\section{0-20 GHz Images of Interior Layers}
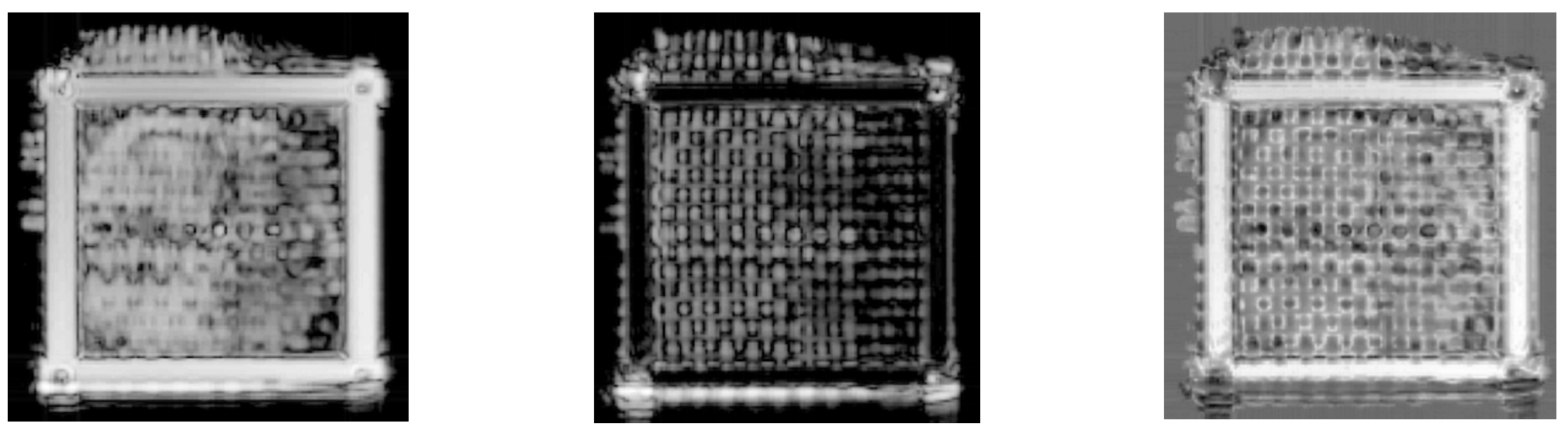

- $10-20 \mathrm{GHz}$ images of undamaged inner layer of test target

- The image at left is L-R polarization associated with direct return

- The center image is $\mathrm{R}-\mathrm{R}$ return associated with multiple scattering

- The image at right is the difference. 


\section{Millimeter Waves: 40-60 GHz}
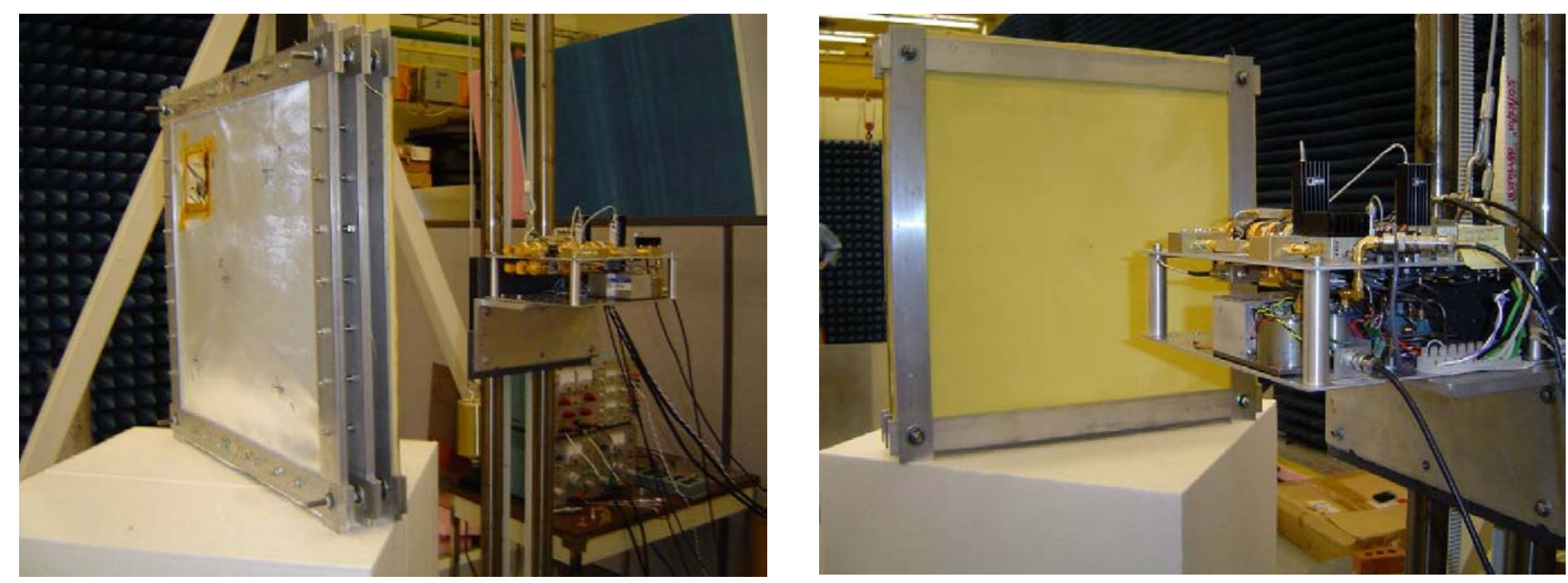

- Measurements were performed at Pacific Northwest National Labs

- Linearly polarized transceiver with a frequency range of 40-60 GHz

- 0.44 meters standoff.

- The transceiver was scanned horizontally and vertically to form a synthetic aperture of $1 \times 1$ meter dimension.

- Expected resolution is approximately $7.5 \mathrm{~mm}$ in range and $3.0 \mathrm{~mm}$ in crossrange. 


\section{0-60 GHz Image of Target Damage}

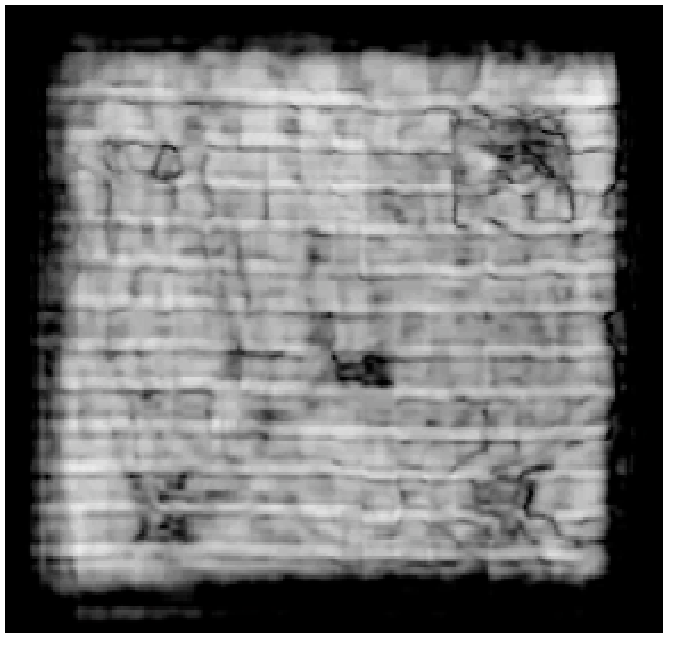

Back Wall Image

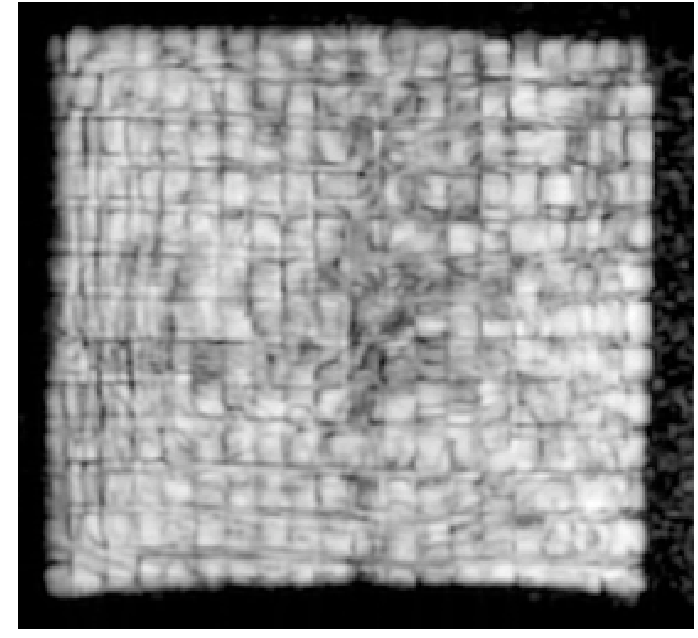

Interior Wall Image

- H-H polarized images of test target.

- At left is return from reflecting aluminum and MLI at rear of target. (With a reflecting aluminum layer at the back wall, the image creates a shadow pattern detailing the MMOD incursions even though the imaging system is set up in a reflective mode.)

- At right is direct return from Kevlar web layer. 


\section{Terahertz Imaging (50 GHz - $1 \mathrm{THz}$ ) of Interior Layer}

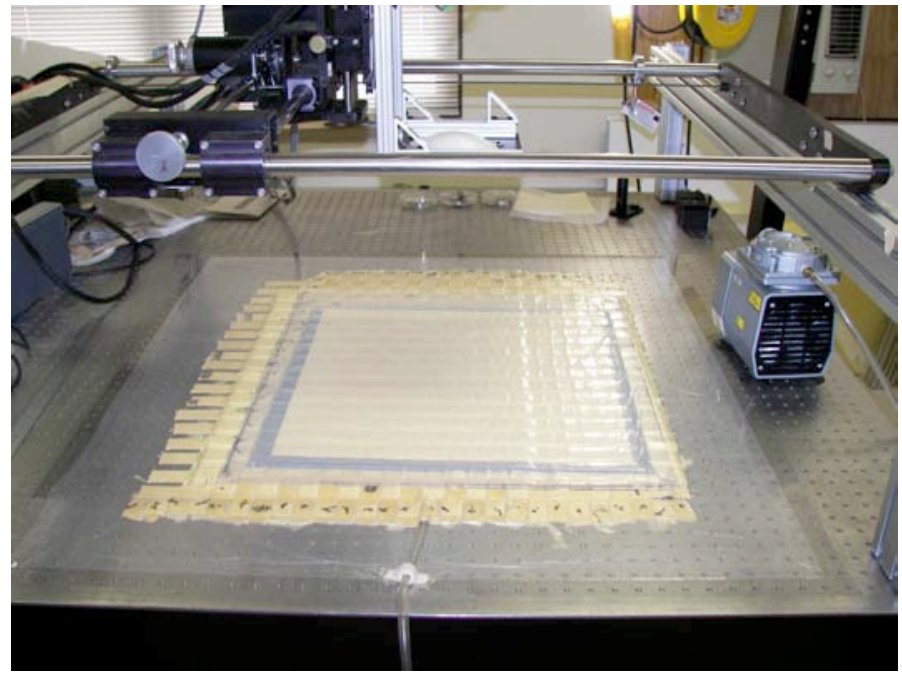

Terahertz scanner

Confocal transceiver, linearly polarized, with a 12 " focal distance.

Layers are under vacuum to create a pressure that pushes inner layers against the restraining layer.
Scan area of interior layer
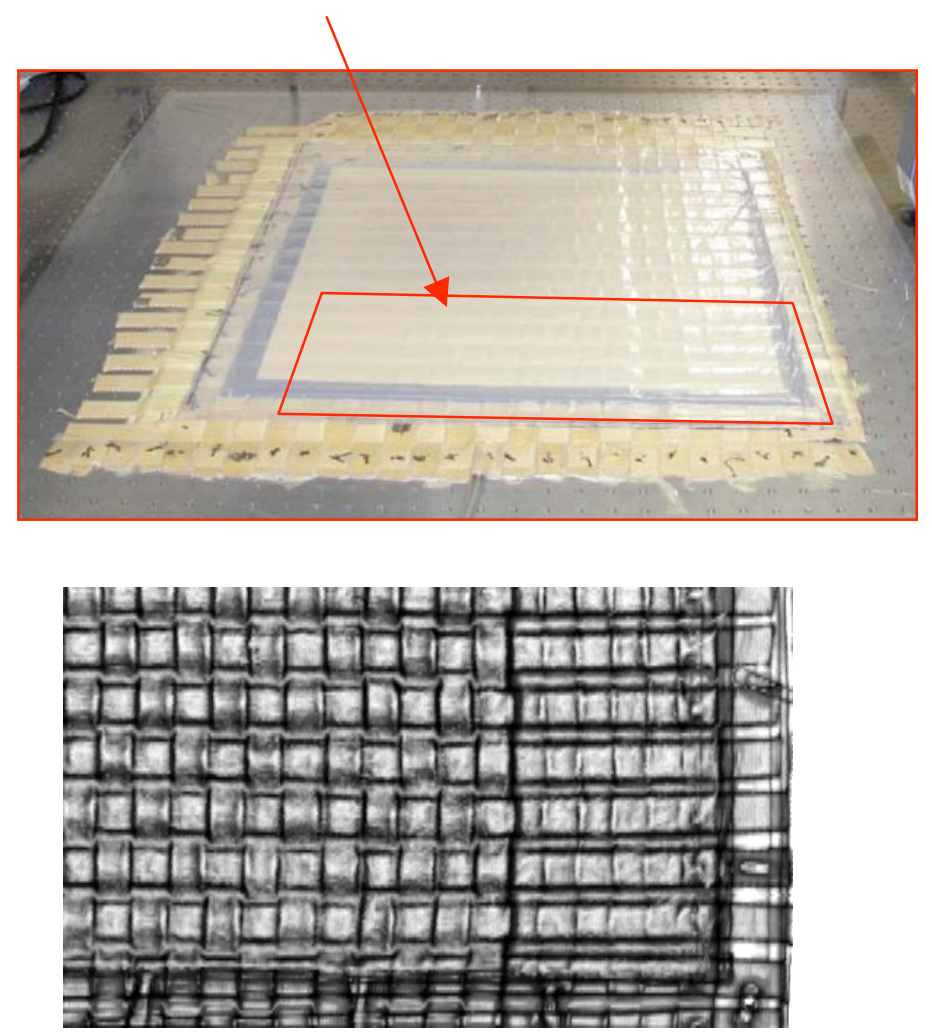


\section{Terahertz Imaging of Damaged Belt and Bladder}
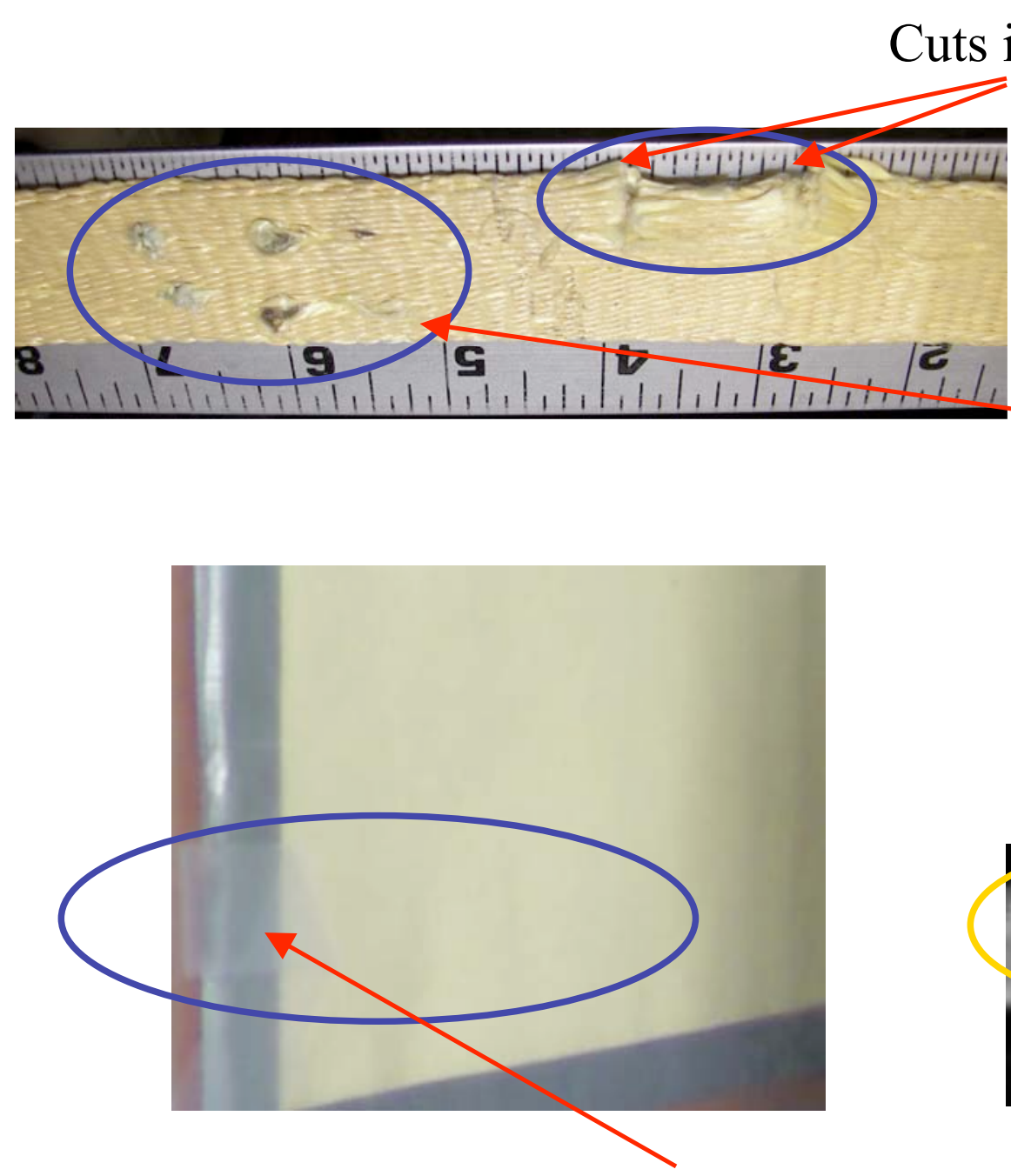

Damaged plastic bladder layer inserted in between front layers.

Holes in plastic bladder layer

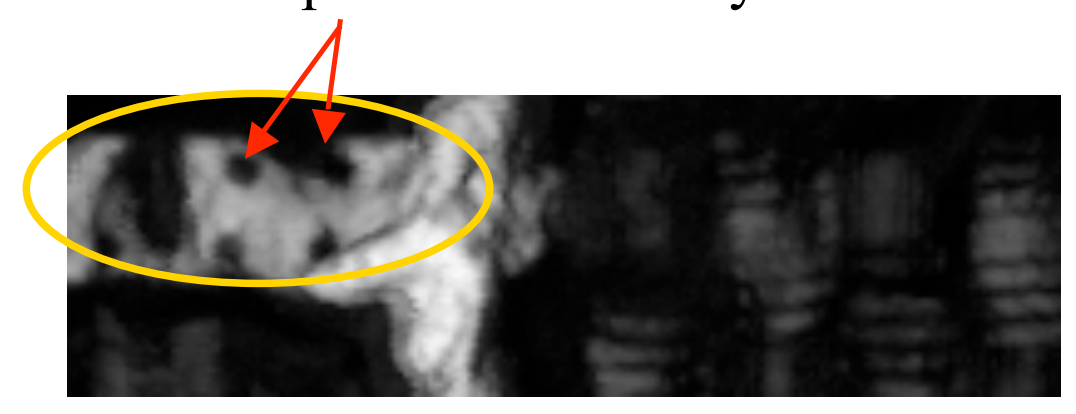

Holes in Kevlar belt (which was woven back into the restraining layer in the terahertz image).

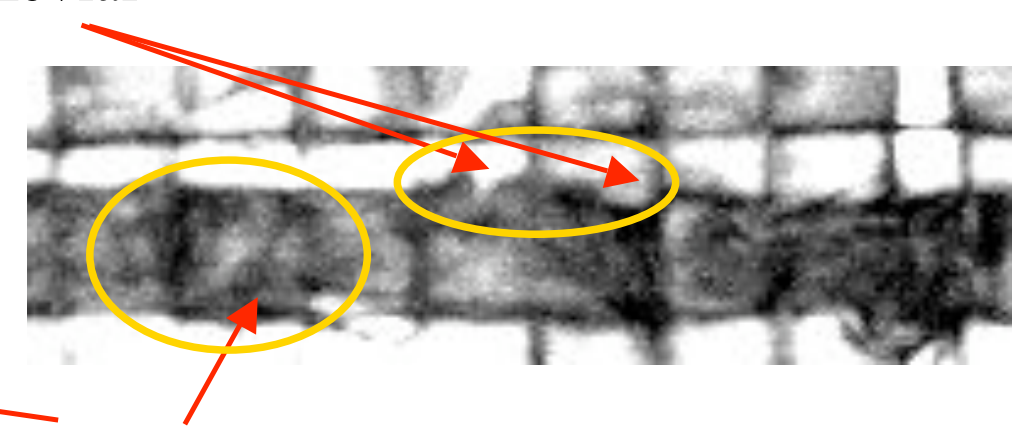

\section{Damaged plastic bladder layer inserted in between front layers.}

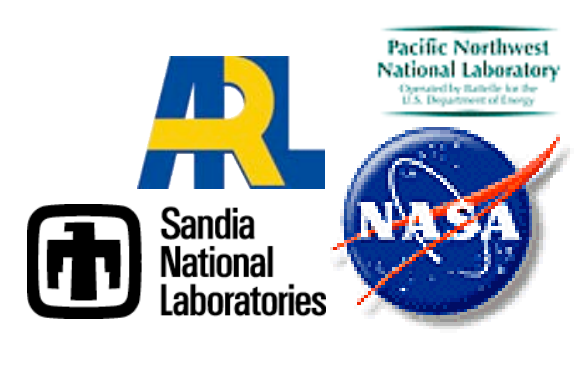




\section{Conclusions}

- Ultrasound was not effective in penetrating the inner layers.

- For through transmission thermography, thin polyethylene insert with holes were slightly visible with through thickness heating, but damage in Kevlar webbing was not detectable. This method is not practical for typical configurations of the structure.

- Several electromagnetic radiations wavelengths were effective in imaging the inflatable habitat walls in a reflection mode (transmitter and receiver were on the inside of the module).

- Different frequencies were more effective at different layer depths.

- Microwaves at 10-20 GHz.

- Effective at measuring the back walls.

- Microwaves at 40-60 GHz.

- Could image the front and back walls.

- Terahertz imaging.

- Could detect small flaws in the plastic layer (bladder).

- Could detect flaws in the Kevlar belt.

- Cuts in the belt's edge were discernable.

- Small holes were discernable.

- Was able to detect the hypervelocity impact damage depth into front layer's MMOD shield layers.

- Energy could reach the back MMOD shield layers although the images were modulated by the intervening layers. 


\section{Image Resolution}

- Image resolution is determined by the wavelength and the angular extent of the illumination

- The angular extent can be limited by the size of the aperture (aperture limited), or by the beamwidth of the antenna (antenna limited)

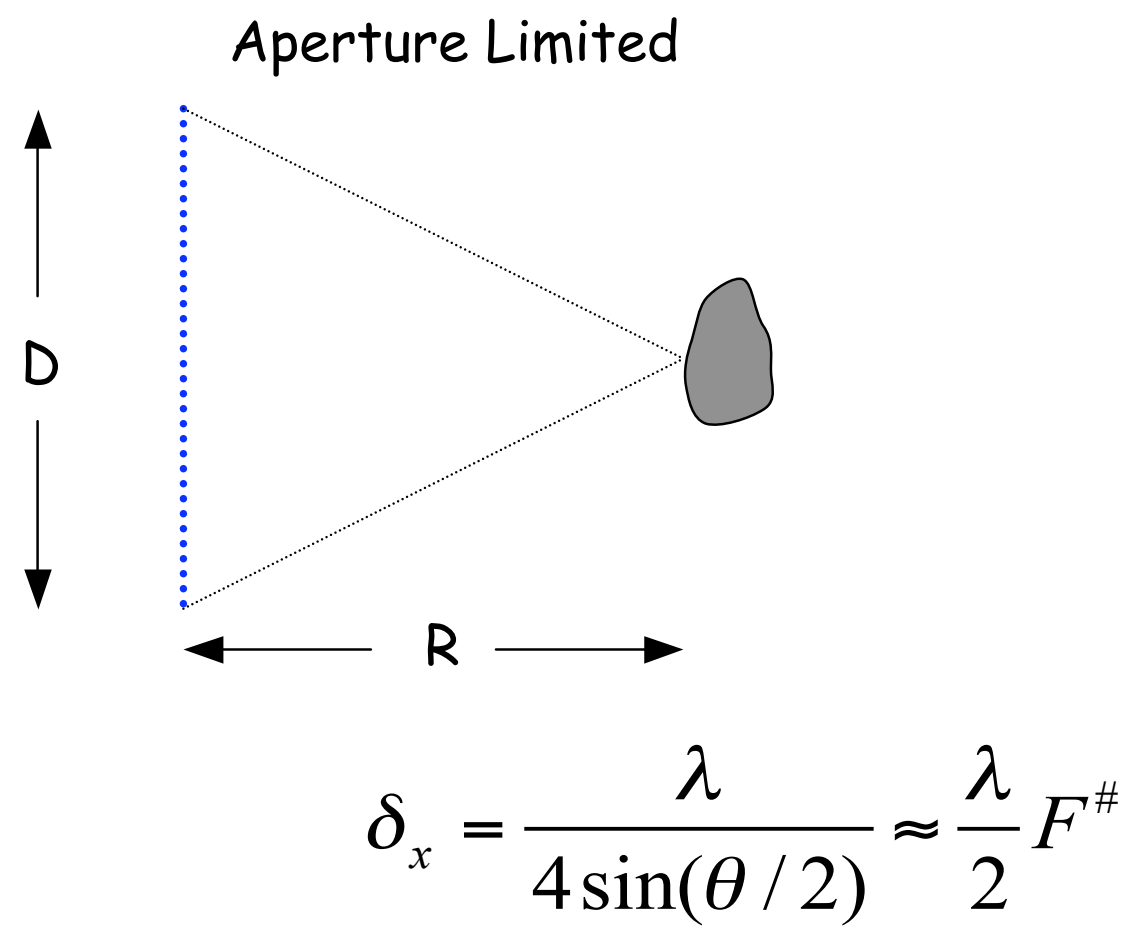

Antenna Limited

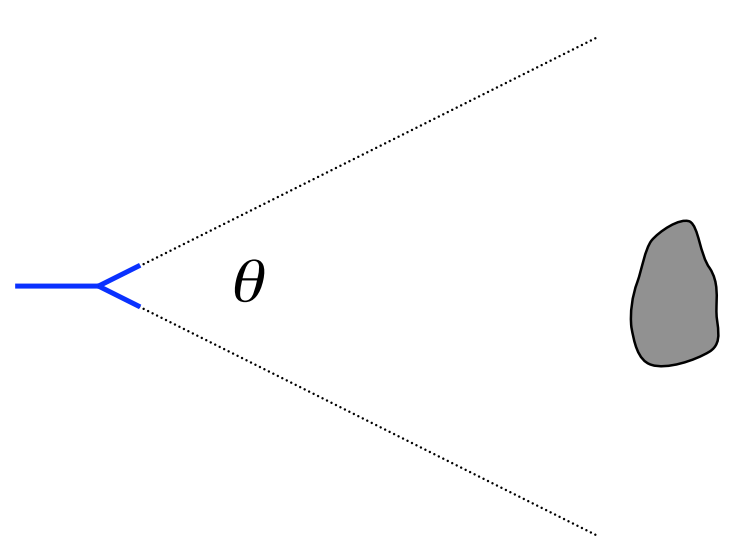

where $F^{\#}=\frac{R}{D}$ 